Florida International University FIU Digital Commons

$1-9-2003$

\title{
The effect of basketball sport aerobics on basketball skill development for fifth grade students
}

William J. Elizuk

Florida International University

DOI: $10.25148 /$ etd.FI15101289

Follow this and additional works at: https://digitalcommons.fiu.edu/etd

Part of the Higher Education Commons

\section{Recommended Citation}

Elizuk, William J., "The effect of basketball sport aerobics on basketball skill development for fifth grade students" (2003). FIU Electronic Theses and Dissertations. 3136.

https://digitalcommons.fiu.edu/etd/3136 
FLORIDA INTERNATIONAL UNIVERSITY

Miami, Florida

THE EFFECT OF BASKETBALL SPORT AEROBICS

ON BASKETBALL SKILL DEVELOPMENT

FOR FIFTH GRADE STUDENTS

A dissertation submitted in partial fulfillment of the

requirements for the degree of

DOCTOR OF EDUCATION

in

HIGHER EDUCATION

by

William J. Elizuk

2003 
To: Dean Linda Blanton

College of Education

This dissertation, written by William J. Elizuk, and entitled The Effect of Basketball Sport Aerobics on Basketball Skill Development for Fifth Grade Students, having been approved in respect to style and intellectual content, is referred to you for judgment.

We have read this dissertation and recommend that it be approved.

Leonard B. Bliss

Bill Yongue

Kingsley Banya, Major Professor

Date of Defense: January 9, 2003

The dissertation of William J. Elizuk is approved.

Dean Linda Blanton College of Education

Dean Douglas Wartzok University Graduate School

Florida International University, 2003 


\section{DEDICATION}

I dedicate this dissertation to my Lord Jesus, in whom I find my source of strength, and my wife, Mary Elizuk for her unconditional love and confidence in my abilities. To my family and friends for their unyielding faith in me, and encouraging me to always press on. I am especially grateful to Ernestine and Arthur Siegwardt, who made the pursuit of my doctorate studies a possibility. Thank you for helping me fulfill this life long dream. 


\section{ACKNOWLEDGMENTS}

To all of my committee, I wish to express my appreciation for your guidance and encouragement. Though the battle was long, I could not have accomplished this goal without the team effort of all of you.

To Dr. Bliss, thank you for constantly going that extra mile on my behalf. Your advice and unyielding commitment to help me through this project is greatly appreciated.

To Dr. Yongue, thank you for being supportive and for your willingness to conduct chapter reviews on weekends. Thanks also for reminding me that life is a process wherein sometimes you just need to take the ride more slowly.

To Dr. Banya, thank you for patience and continual support and sticking with me despite all odds. Your advice and suggestions were always appreciated.

To Dr. DiVesta, thank you for you effective critique throughout the dissertation process. It enabled me to reflect and refine my thoughts in order to meet the dissertation standards.

To Dr. DeFrancisco, thanks for your tremendous support, you are a confidence builder!

To the many colleagues and department members who provided encouragement, I thank you.

To my family in Canada, your calls of concern, encouragement and prayers always made me feel loved. Thanks for believing in me.

Thank you to the dedication of the team of teachers who conducted the pre and post studies. Your efforts provided the statistical data necessary to complete this project. 
Thank you to Amy for your cheerfulness while assisting me in converting the data into stats.

Thank you to Sharon Hamel, your patience, editing skills, friendship and direction mean so much to me.

Thank you to my family and friends, too many to mention, who supported me every step of the way.

An extra special thank you to Roy and Vivian Carlson for your continual prayers and friendship. Thanks for reminding me that I can do all things through Christ who strengthens me. I cherish our friendship.

Thanks to the many authors whose research has sparked my interest and created this dedication in me to make a difference in the health of youth and adults. Hopefully, this is just the beginning. 


\title{
ABSTRACT OF THE DISSERTATION
}

THE EFFECT OF BASKETBALL SPORT AEROBICS ON BASKETBALL SKILL

\section{DEVELOPMENT FOR FIFTH GRADE STUDENTS}

by

\author{
William J. Elizuk
}

Florida International University, 2003

Miami, Florida

Professor Kingsley Banya, Major Professor

The purpose of this study was to investigate the effectiveness of an experimental teaching method, Sport Aerobics, on the basketball skill acquisition of fifth grade students. This study investigated the differences in the shooting, dribbling, and passing scores of students taught with Sport Aerobics instruction compared to those taught with a traditional method, Practice Style. Sport Aerobics is an instructional method based on a theoretical framework developed by the researcher to enhance skill acquisition. This framework leads to teaching strategies such as using immediate feedback and specific cueing; arranging for students to engage in object free movement; arranging lessons, according to the framework's concept of movement progression, into lessons staged according to skill and sub-skill complexity; and instructing based on whole group organization. Sport Aerobic instructional strategies were designed to facilitate process learning that is recognized as important in today's development learning approach for age related curriculums. In contrast, the traditional Practice Style uses product-oriented strategies. 
Four classrooms, consisting of seventy-nine fifth grade students from two physical education programs, at different locations, were randomly assigned to two treatments; Sport Aerobics and Practice Style for instruction over a 15 period curriculum. Using the American Alliance Physical Education Recreation \& Dance tests, both groups were pretested and posttested for skill achievement of shooting, dribbling, and passing. Pretest and posttest skill score samples were collected and evaluated. ANCOVAs were performed on the posttests adjusted for the pretests to determine whether or not there would be greater achievement of skills with the Sport Aerobics method. Results failed to establish significant scoring differences between the two methods. Based on the literature and study findings a recommendation is made that longer lesson units will assist in the investigation of the effectiveness of both the instructional model and the individual elements that facilitate skill acquisition. 


\section{TABLE OF CONTENTS}

CHAPTER

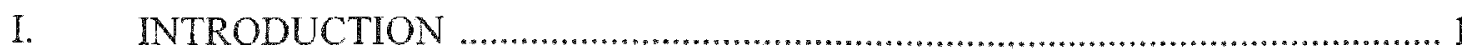

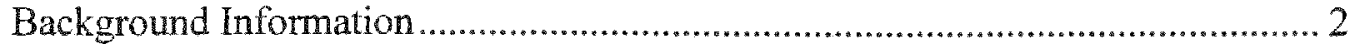

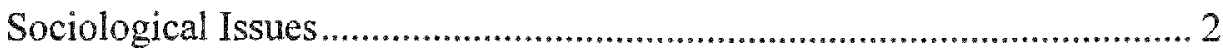

Pedagogical Issues ..................................................................................... 3

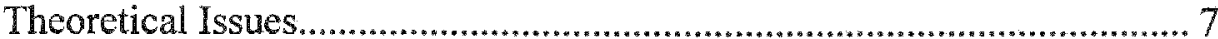

Statement of the Problem ................................................................................ 12

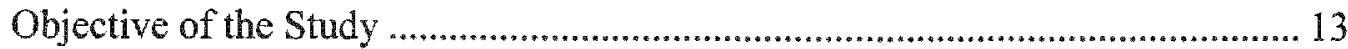

Research Questions ............................................................................................ 14

Hypotheses of the Study ..................................................................................... 14

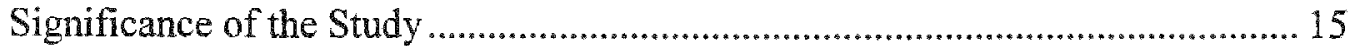

Limitations of the Study.................................................................................. 16

Definitions of Key Terms ................................................................................ 16

Summary of the Chapter ................................................................................... 17

Organization of the Study ................................................................................ 17

II. REVIEW OF THE RELATED LITERATURE............................................... 19

Physical Fitness and Inactivity......................................................................... 19

Developmental Process: Learning Fundamental Movement Skills ...................... 21

Curriculum Strategies to Enhance Learning in Physical Education ..................... 26

Variation in Teaching Practices .............................................................................. 27

Corrective Feedback and Cueing .......................................................... 27

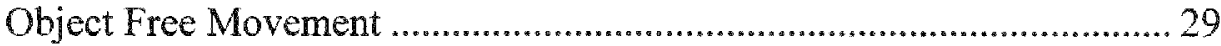

Movement Progression ............................................................................. 31

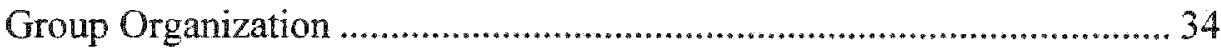

Length of Practice Time............................................................................... 37

Internalization.................................................................. 38

Conceptual Framework for Skills Acquisition ................................................... 39

Summary of the Chapter ......................................................................................... 43

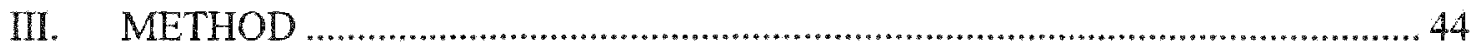

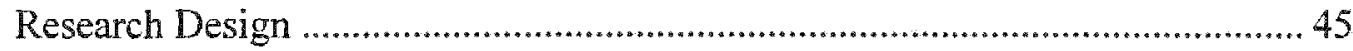

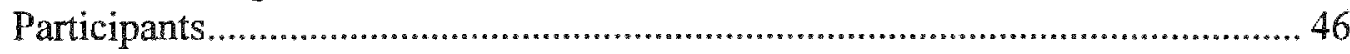

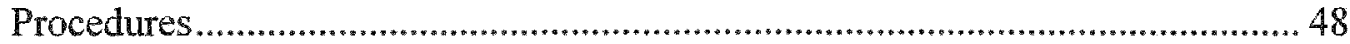

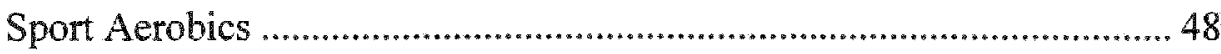

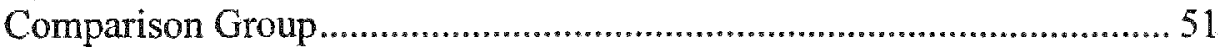

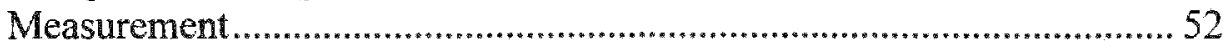

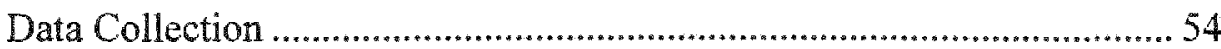

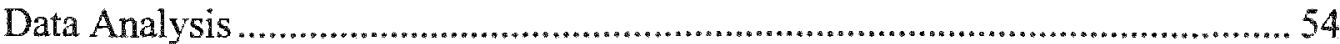

Summary of the Chapter ................................................................................ 55 


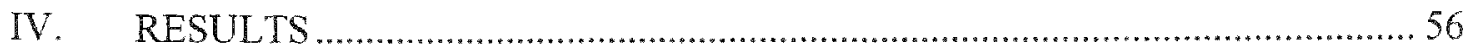

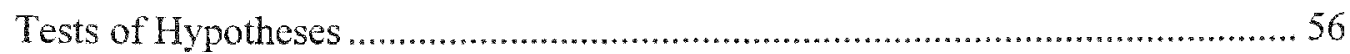

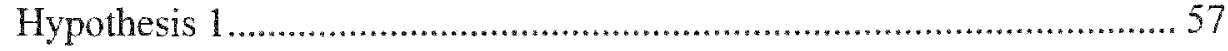

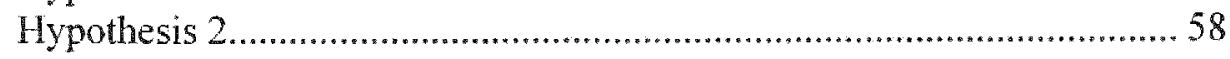

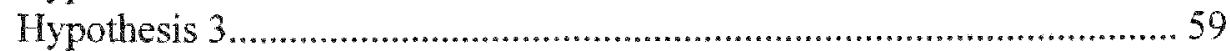

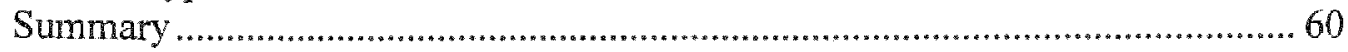

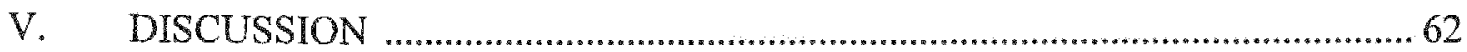

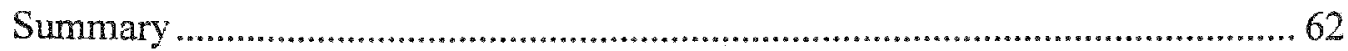

Effects of Lessons on Basketball Shooting Scores .....................................62 62

Effects of Lessons on Basketball Dribbling Scores ....................................6 63

Effects of Lessons on Basketball Passing Scores ..................................... 63

Discussion ....................................................................................................... 64

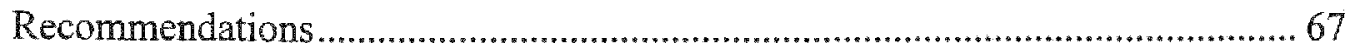

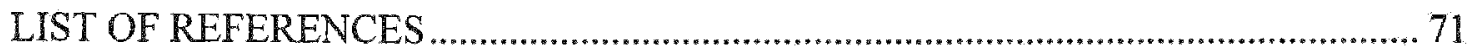

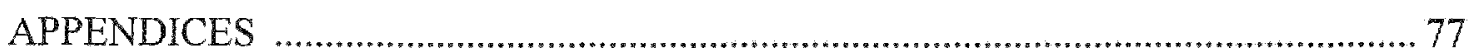

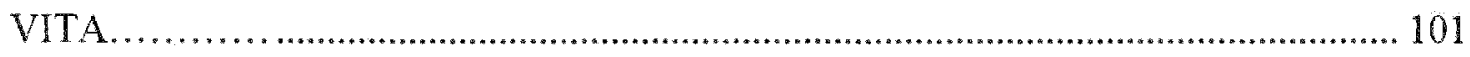




\section{LIST OF TABLES}

TABLE

1. Comparison of Variables of Practice Style and Sport Aerobics Models of Learning. 42

2. Descriptive Statistics for Students Using the Sports Aerobics Strategy 56

3. Descriptive Statistics for Students Using the Practice Style Strategy 56

4. Analysis of Covariance for Basketball Shooting.. 57

5. Analysis of Covariance for Basketball Dribbling. 58

6. Analysis of Covariance for Basketball Passing 59 


\section{CHAPTER I}

\section{INTRODUCTION}

According to the Surgeon General and researchers of the United States Department of Health and Human Services (USDHHS) a majority of the children in this nation lack fundamental motor skills, which has led them to exhibit extremely low levels of physical activity (USDHHS, 1996). Consequently, concerns have risen in the field of physical education regarding the methods being utilized by instructors to teach and enhance motor skill acquisition of children. Critics have suggested that many of the Practice Style methods presently being used are antiquated and originate from a philosophy associated with developing elite athletes as opposed to providing opportunities for all students to develop their individual skills (Rink, 1993).

Practice Style method is most prevalent in practice activity classes, which teach specific sport skills. In this study, its effectiveness was compared to an experimental instructional method called Sport Aerobics. The Sport Aerobics method is comprised of teaching strategies such as using immediate corrective feedback and specific cueing, along with whole group instruction, arranging for students to engage in object free movement, and has lessons based on teaching movement progression. According to experimental research, these components positively influence skill acquisition. The study used a 15-class unit, which is typical of a physical education program to determine the effects of the two methods on treatment outcomes of fifth grade students' basketball skills. A pretest and posttest assessment of the students' basketball skills were administered to determine which was the more effective strategy for skill acquisition. 


\section{Background Information}

This research project was developed out of the researcher's study of several interlocking sociological and educational issues. The latter includes important pedagogical and theoretical issues in the field of physical education.

\section{Sociological Issues}

Within the United States, increasing concern has arisen over the widespread presence of physical inactivity in the general population. There is increasing recognition being given to the severity of this problem. More than half of U.S. adults do not meet recommended levels of moderate physical activity and one-fourth have been found to engage in no leisure time physical activity at all (USDHHS, 1996). According to the National Institute of Health (NIH, 1995; USDHHS, 1996), physical inactivity is more prevalent among those with lower income and education levels and, beginning in adolescence, affects more females than males

While the benefits of physical activity have been well documented, as have the detriments resulting from the lack of such activity, the fitness levels of children in the last decade have declined by $6 \%$, and fewer children are choosing to participate in school physical education and sport activities (Rotella, Hanson, \& Coop, 1991). As reported by the Center for Disease Control (CDC) between 1991 and 1997, only one-half (52\%) of all high school students were enrolled in physical education (CDC, 1997). One-third (32\%) attended physical education class daily, and $24 \%$ of students who were enrolled in physical education were physically active less than 20 minutes during a typical physical education class. Although physical education enrollment in the total student population did not change between 1991 and 1997, previous research suggests that physical 
education enrollment among high school students was greater in $1984(65 \%)$ than it is currently (Ross, Dotson, Gilbert, \& Katz, 1985). As reported by this 1997 CDC study, the numbers of students attending daily physical education classes decreased significantly among both female and male students; Black, Hispanic, and White students; and among students in every grade except 12 th grade. In response to the overall problem, increasing efforts have been devoted to examining the factors influencing participation in physical activity. Most importantly, as reported by the researchers, the $\mathrm{CDC}$ report demonstrates the need for greater commitment of communities, and the need for teachers and school officials to strengthen their efforts to insure that quality daily physical education is offered to all students.

Pedagogical Issues

Those coaches and teachers responsible for teaching motor skill acquisition are increasingly being asked to use developmentally appropriate standard outcomes for all children, regardless of the children's ability, age, gender, or other characteristics. Associations such as the National Association for Sport and Physical Education (NASPE) have been established to design and publish national competencies and proficiency standards for every grade level from $\mathrm{K}-12$. These guidelines are to assist educators and fitness advocates in helping children obtain appropriate achievement outcomes that are based on specific goals and objectives (NASPE, 1995a).

According to these research reports, a majority of the children in this nation lack fundamental motor skills. This deficiency has led to their disinterest in physical education and to their extreme levels of inactivity. Consequently, concerns have arisen regarding the methods used by teachers and instructors to teach and motivate children in 
motor skill acquisition. Critics have suggested that many of these methods are antiquated and originate from a philosophy associated with the development of elite athletes as opposed to provision of opportunity for all students to develop their individual skills (Rink, 1993). The problem is compounded because teachers and instructors have indicated that inevitably there is a wide range of student skill levels present within the learning environment. These issues complicate instructors' attempts to apply effective instruction and teaching strategies (Griffin, 1996).

The search for effective methods is further complicated by evidence that suggests that both reliance on traditional teaching methods and failure to offer adequate skill practice activities critically impact the development of motor skills and movement for children, especially for females and unskilled males (Garcia, 1994). As documented within the literature, teachers and instructors have also expressed concern over the lack of systematic assistance they have received in the development and implementation of teaching strategies. Teachers and instructors have found that their traditional practice methods are not effective in overcoming poor motor skill acquisition in children. This is especially important because adolescents' desire to participate in physical activity is affected by the motor skill competence they developed as children.

As this acknowledgment has become widespread in the field of physical education, efforts have been directed toward shifting from a purely maturational perspective (skills acquired solely through age maturity) to that which is known as developmental programming (skills acquisition is a staged developmental process that is age appropriate, not age dependent.) Consequently, researchers now widely consider the appropriate pedagogical approach for children to acquire the fundamental movement 
skills of childhood to be quality-defined physical activities that incorporate developmental programming and effective instruction, as opposed to relying on age related games and drills.

Developmental programming is based on the fundamental proposition that although motor development is age related, it is not age dependent (NASPE, 1995b). Therefore, decisions by teachers and instructors regarding movement instruction are based on deciding what to teach, when to teach it, and how to teach it on the basis of the appropriateness of the activity for the individual. Such decisions are now only secondarily determined by consideration of the appropriateness of the activity for a certain age group. Currently the primary consideration is age dependent driven activities. Through the application of an age related approach, the tasks associated with planning and structuring physical activities for children are refocused. The emphasis is now on development of each individual child's cognitive and affective domains, as well as the psychomotor domain. Researchers have found that this age related approach is necessary if sequential movement skills and increased physical competency are to be achieved (NASPE, 1992).

A fundamental principle associated with developmental programming for children is process outcome learning. This is best facilitated by an approach that emphasizes simple to complex, and general to specific development. Such an approach is contrary to more commonly used methods of instruction to teach skill development practices. For example, the traditional Practice Style method promotes product outcomes as opposed to process outcomes. School practices including short teaching units, minimal numbers of physical education class periods, large class sizes, lack of equipment, and lack of 
effective alternative teaching methods have led to continual use of product oriented skill instruction. Objectives of the Practice Style method are the following: (Mosston \& Ashworth, 1986, p.25).

1. To practice the assigned task(s) as demonstrated and/or explained.

2. To approximate as much as possible, the performance of the assigned $\operatorname{task}(s)$.

3. To realize by experience that proficient performance is related to task repetition.

4. To realize by experience that task performance is related to time.

5. To realize by experience that proficiency performance is related to knowledge of results.

6. To realize by experience that the knowledge is obtained from various forms of feedback offered by the teacher.

In this method of instruction, the teacher learns to trust the learner to make appropriate decisions while doing the task. The learner in this method learns deliberate and independent decision making in conjunction with the performance of the task. The essence of this style, then, is a particular cycle of relationships between the teacher and the learner; the teacher presents the task, the learner performs it for a period of time; then the teacher observes the performances and offers feedback. The critical factors in the Practice Style method are: (a) use of time, (b) decision making of the learner, and (c) teacher communication to all of the students. 
The concern for this method of learning is whether the learners' independence to make decisions during this style of instruction promotes product results as opposed to process learning that ultimately effects a higher level of skill acquisition.

\section{Theoretical Issues}

As the need for daily physical education in the lives of children has become increasingly evident, concern continues to be directed towards alleviating the factors that prevent children from participating fully in physical education activities. A lack of motor skill acquisition in early childhood is one such factor. Evidence suggests the motor development of elementary school children has not kept pace with their cognitive development in chronological age, in spite of the fact that there is growing emphasis in the physical education field on the importance of bodily/kinesthetic intelligence. There has been a growing recognition that historically the process by which children develop motor skills has largely been based on adherence to a theoretical assumption that suggests that children will somehow automatically acquire and develop motor skills as a result, and over the course of, the maturation process (Gallahue \& Ozmun, 1995).

Consequently, there has been a tendency to rely on the use of group games and/or group play activities rather than focusing on effective methods to assist children in acquiring their fundamental movement skills (e.g., running, jumping, throwing, catching, kicking, and balancing.) Application of such an approach during the early years of a child's development results in the potential for later difficulty in efforts to progress to more complex skills, such as those found in sports (e.g., basketball lay-ups, soccer dribbling, and volleyball spiking.) 
Teachers of physical education and sport have long been concerned that traditional approaches to teaching sport have done little beyond developing inert skills that have little reasonable chance of being used in a real setting. The real and authentic setting for sport activities in this context is the game. The ultimate goal of sport instruction is for students to be able to play the game with enough skill to accrue the many and varied benefits of participation. Traditionally, physical educators have taken at face value the notion that before one can play the game, an individual must at least have some level of proficiency in the motor skills that are part of the game. A study of motor skills must involve the factors that influence motor skill learning and the processes underlying the learning of skills. Physical educators spend much of their time planning, carrying out, and evaluating instruction, in order to find the most effective method of instructing skill activities. Although there are several bases that can be used for decision making, such as past experience, following methods prescribed by former teachers, written literature and so forth, there is a basis for instructional decision making that is often overlooked. This base is the one established by evidence obtained from motor learning research.

Among the instructional strategy variables that research postulates influence skill acquisition are immediate feedback and specific cueing, object free movement lessons, staged lessons based on the principles of movement progression, simultaneous group organization, and practice sessions of at least 30 minutes.

Immediate feedback and specific cueing. Based on the studies conducted by Rikard (1992) and Graham and Heimerer (1981), providing individual feedback has been shown to be critical to skill acquisition. It is the first key instructional element to 
teaching the process of learning a skill. These researchers recommended that learning activities be structured in such a way that all students perform the skill movements simultaneously, lending more opportunities for teachers to observe and provide necessary and specific feedback and cues associated with the skill movement. For example, any number of students in class could be engaged in practicing the same body position as in a basketball lay-up take-off and hold that position while the instructor provides appropriate feedback. This feedback may be general to the group or addressed to specific individuals.

In current Practice Style activities for sport skills, students are distributed into separate groups for practicing the whole skill independently. Unfortunately, this provides less opportunity for teacher corrective feedback or cueing since limited class time prevents individual attention in each group. Theoretically, there would be greater opportunity for individual cueing and feedback in a single group practice structure designed with students moving together and both directly visible and in proximity to the instructor. As a result of immediate feedback, students could readily respond to the teacher's specific cueing instruction and make appropriate movement changes that would accommodate successful skill acquisition.

Object free movement. Another relevant factor in skill acquisition is object free movement. As suggested within the literature, lack of object control may be the primary reason studies have not been able to demonstrate improvement in many strategy and skill variables that use objects. (Rink, French, \& Tjeerdsma, 1996; Turner \& Martinek, 1992, 1995b). According to Rink et al. (1996), the tendency in physical education skill development programs is to put a major emphasis on accuracy in manipulative skills. In 
a six week study of elementary students' skill acquisition, the researchers found that a more appropriate approach is to help students learn how to use their bodies both with and without implements to assist in producing required mechanics and force control outcomes. The students who used non implement practice as part of their instructional strategy prior to implement practice, improved more than the group who practiced for the same length of time, but only with the implement.

Traditionally, Practice Style activities in physical education immediately engage learners with implements such as cones on the floor, basketballs, and basketball hoops during a lesson in basketball skill acquisition. Theoretically, based on the object free method of skill acquisition, learners would learn movements and mechanics without implements, in order to maximize their focus on kinesthetic awareness that research has reported to contribute to higher levels of skill development (McPherson \& French, 1991; Rink, French, \& Tjeerdsma, 1996)

Movement progression. Both the Recall Schema Theory (Schmidt, 1975) and the simple to complex approach (English, 1983) advocate learning conditions that encourage skill acquisition based on the concept of movement progression. These methods suggest providing instructional experiences for learners designed to present a progression of content that depends on success of correct trials. This indicates the basic assumption that beginner levels of skill needed to be taught before more complex versions are presented. Additionally, the Recall Schema contends that merely practicing movement patterns as a whole is not sufficient, but that patterns must be practiced using appropriate mechanics in a simple to complex manner to achieve specific skill acquisition memory patterns. 
Performance outcome is the dominant approach for Practice Style physical education programs. Primarily concerned with performance results (e.g. successful baskets), Practice Style instruction is driven by current school conditions including short class periods, large class sizes, instructional goals set through cultural elitism, and limited support for adopting a teaching progression strategy. An alternative method to common Practice Style classes would be to engage learners in an activity structured to promote movement progression with a step by step mechanical system of learning specific skills. For example, a teacher would plan to teach a complex skill, such as basketball shooting, with the initial goal of students learning how to move their bodies step by step rather than shooting successful baskets. The first day of class, footwork would be practiced, the second day body positions, the third day arm positions, and so on.

Simultaneous group organization. In implementation of the Practice Style method most physical education classes frequently engage in practice activities in organized multiple groups. Multiple groups allow facilitation of independently structured equal practice time for students performance task(s). This organization promotes equal practice time, but not necessarily good time management for short classes or sufficient practice trials needed for the unskilled. Hastie (1996) suggested that whole class instruction was more effective when students were initially practicing new skill. This allowed direct and continual feedback with the learner during the basic movement learning phase of the skill. He also suggested that once the fundamental movements were practiced, then smaller group or individualized refinement practice with close monitoring seemed to be more effective. Therefore, combining whole group fundamental practice 
with individual or small group refinement practice is theoretically supported as an effective approach to class organization during skill teaching.

Appropriate length of practice time. Another variable that can have varying effects on skill acquisition is the length of practice time. Rink et al. (1996) reported that numerous physical education studies have been unable to demonstrate any significant difference or change from pre to post test scores for skill acquisition. Rink et al. (1996) indicated that those studies might not have been conducted for a long enough period for any learning to occur. These studies that did not show a significant difference or change conducted nine classes or less. Studies from French, Werner, Hussey, Taylor, and Jones (1996); Turner and Martinek (1995b); McPherson (1992) and other skill acquisition studies all showed improvement with 15 classes of 30 minutes teaching at least four skills.

In addition, Baddeley and Longman (1978) recommended shorter lengths of practice time over longer time periods, rather than longer practice sessions over shorter time periods. Baddeley and Longman also suggested that in order to increase motor skill development, implementing individual practice time was preferable to increasing the duration of the class period.

In summary, researchers have indicated a concern for inactive youth and the need for investigative research relating to effective teaching methods.

\section{Statement of the Problem}

Based on reports from the Surgeon General (U.S.D.H.H.S., 2001), and researchers (Rotella et al., 1991), a majority of the children in this nation lack fundamental motor skills which has led them to both a disinterest in physical education 
and extreme levels of inactivity. While there is literature about factors that affect skill acquisition, within this body of literature, this researcher was unable to find anything specifically about combined strategies that may improve facilitation of the skill acquisition process.

Concerns have arisen regarding the methods used by teachers and instructors to teach and provide outcomes in children's motor skill acquisition. Critics have suggested that many of the methods that teachers and instructors are currently employing are antiquated and originate from a philosophy associated with the development of elite athletes, as opposed to providing the opportunity for all students to develop their individual skills (Rink, 1993). Well documented within the literature are teachers' and instructors' concerns over the lack of systematic assistance and accompanying instructional methods that would aid them in the development and implementation of effective teaching strategies. Physical education instructors increasingly want to be more effective in their efforts to overcome the deficiencies found to be associated with children's poor motor skill acquisition and low levels of participation in physical activity (Garcia, 1994).

This case study explored the effectiveness of an experimental method to enhance motor skill acquisition in elementary school children with basketball skill achievement.

Objective of the Study

The purposes of this study were to investigate (a) the effectiveness of an experimental education teaching method, Sport Aerobics, on basketball shooting, dribbling, and passing skills acquisition of grade five physical education classes and (b) the degree to which fifth grade children taught with Sport Aerobics instruction improve 
in basketball shooting, dribbling and passing. It was the intent of this study to compare their skill acquisition scores with children who were taught with a traditional Practice Style method to see if Sport Aerobics was more effective in a typical 15-week instructional time period.

\section{Research Questions}

Given these objectives, the general question that guided this study was: At the end of the 15 week period of instruction, what differences would there be between an experimental method, Sport Aerobics, and a traditional method, Practice Style, on basketball skill acquisition for fifth grade students?

The research subquestions underlying the study were as follows:

1. Do differences exist between the basketball shooting scores of children who received Sports Aerobics instruction, using a combination of techniques including object free movement, movement progression, immediate feedback, specific cueing, and simultaneous group organization, as compared to the scores of those children who received Practice Style Basketball instruction lessons?

2. Do differences exist between the basketball dribbling scores of children who received Sports Aerobics instruction, using a combination of techniques including object free movement, movement progression, immediate feedback, specific cueing and simultaneous group organization, as compared to the scores of those children who received Practice Style Basketball instruction lessons?

3. Do differences exist between the basketball passing scores of children who received Sports Aerobics instruction, using a combination of techniques including object free movement, movement progression, immediate feedback, specific cueing, and simultaneous group organization, as compared to the scores of those children who received Practice Style Basketball instruction lessons? 


\section{Hypotheses of the Study}

In order to address the research questions, the following hypotheses are proposed: Hypothesis 1. Students receiving Sport Aerobics instruction in basketball shooting will have higher adjusted posttest shooting skill scores than students receiving traditional Practice Style instruction.

Hypothesis 2. Students receiving Sport Aerobics instruction in basketball dribbling will have lower adjusted posttest dribbling skill scores than students receiving traditional Practice Style instruction.

Hypothesis 3. Students receiving Sport Aerobics instruction in basketball passing will have higher adjusted posttest passing skill scores than students receiving traditional Practice Style instruction.

\section{Significance of the Study}

The primary significance of the study is the contribution to the knowledge base in the field of physical education, especially as it applies to fundamental motor skill acquisition. The literature abounds with research on ameliorating the educational process within physical education curriculum. However, the researcher found a noticeable lack of information or research on experimental methods of skill acquisition activities or curriculums. The researcher felt that the experimental method chosen for this study had valuable knowledge to contribute to the professional knowledge base.

This study therefore, seeks to add to the body of knowledge by analyzing the effectiveness of the experimental method, Sport Aerobics, on teaching basketball skill acquisition. In contributing to the knowledge base, this researcher has anticipated, that the information provided will be utilized to assist in increasing the academic success of 
physical education classes in producing children with appropriate fundamental motor skills, while decreasing inactivity. In the long term, physically skilled and active children are more likely to become healthy active adults.

This study also has significance for teachers and instructors who may use the issues it raises to find ways to add strategies to their curriculum and instruction that both facilitate better class management through good use of feedback and cueing (Rikard, 1992), and facilitate skill acquisition despite equipment limitations (Silverman, 1993).

Another significance is to provide a discussion of issues and research to stimulate teachers to become critical thinkers who reflect on the strategies that they use to enhance motor learning and practice. The issues raised by the study may catalyze teachers to change, reach beyond the confines of their traditional methods to affect children of all ages and abilities.

\section{Limitations of the Study}

Students who participated in the study were from the Miami, Florida area. Due to this constraint, it is not possible to generalize the findings of the study to all fifth grade students within the United States. The findings of the study can only be generalized to other children, classrooms and teachers similar to those who participated in the study.

\section{Definitions of Key Terms}

For the purposes of the study, the following words and phrases have special meaning and are key terms associated with the study. Other terms which are not frequently used but which require definitions are explained as they are introduced.

Participation Patterns. Personal freedom and voluntary choice of sports-related activity describable by the level of participation and type of activities chosen. 
Practice Style Sport Skill Development Method. Explanation, demonstration, drills, and practice of fundamental sport skills.

Sport Aerobics. An aerobic dance method of exercise using music and a combination of a variety of sport skill movements from both individual and team sports.

Sport Skill Development. The exploring of one's psychomotor capacities through specific fundamental movements of various sports in order to improve one cognitively and physically for increased confidence to perform.

\section{Summary of the Chapter}

Chapter One has provided an overall introduction to the study. An overview was provided of the factors and issues as well as impact related to the current trend of lack of physical activity engaged in by children within the U.S.. In delineating this problem, the degree to which the current status of physical education in the U.S., and the association between motor/movement skill development and children's successful engagement in physical activity was discussed. Relevant background information was reviewed as it relates to the need for increased efforts in implementing developmental programming within physical education and physical activity instruction. Subsequently, a theoretical framework that conceptualized the primary principles associated with an educational model based on a developmental perspective was provided. A rationale for the study based on a developmental perspective was presented, followed by a presentation of the research questions underlying the study. The significance and limitations of the study were discussed and key terms defined. 


\section{Organization of the Study}

The remaining sections of this research study are divided into the following chapters.

Chapter II, "Review of the Related Literature", reviews and discusses the related literature on physical fitness and inactivity, on the developmental process of learning movement skills and on curriculum strategies to enhance leaming in physical education. It also discusses the conceptual framework used in this study.

Chapter III, "Method", describes the research design, description of participants, and procedures for data collection and data analysis used in this study.

Chapter IV, "Results", deals with the complete presentation, analysis and evaluation of the research findings.

Chapter V, "Discussion", is based on the findings in Chapter IV. Findings are summarized and discussed. Recommendations for further research are given. 


\section{CHAPTER II}

\section{REVIEW OF THE RELATED LITERATURE}

Literature establishing the importance of finding better methods of teaching children the physically complex skills they will need to be healthy, active adults will be discussed first in this chapter. This will be followed by literature explaining the nature and application of developmental programming, because it has been identified as a fundamental principle of teaching models that can help facilitate and enhance motor/movement skills acquisition (Gallahue, 1997). As well, the literature review will also focus on curriculum strategies that have been identified as a basis for a theoretical framework, for use with children to enhance the process of learning and ultimately, skill acquisition. Children must internalize the information presented through any curriculum. This process will be the next topic reviewed. Then the theoretical framework for this study will be presented.

\section{Physical Fitness and Inactivity}

A pattern of inactivity, also known as sedentism, begins early in life. According to the Surgeon General (2001) regarding physical fitness, obesity is at an epidemic level for children within our nation. Findings indicate that $11 \%$ of six to 11 year olds and $11 \%$ of 12-17 year olds are obese (National Institute of Diabetes, Digestive and Kidney Diseases, n.d., p.8). This finding doubles the prevalence of obesity in children of 30 years ago (CDC, 1997). Due to the severity of this problem, promotion of physical activity among children becomes imperative.

Physical education has now become recognized as an integral part of the total education of the child. National concern with physical education for all children and 
adolescents grew stronger with the release of the findings from the Youth Risk Behavior Surveillance System (YRBSS) in 1997. This assessment, administered by the CDC, established that from 1991 through 1997 there were negative trends regarding the prevalence of physical education enrollment, daily attendance in physical education, and being physically active for at least 20 minutes during physical education class, among all high school students and among demographic subgroups (gender, race/ethnicity, and grade in school) of students. Trends in the numbers of high school students who were physically active in physical education class at least 20 minutes 5 days per week also were examined as a summary indicator of compliance with year 2000 health objectives for school physical education programs (e.g., daily physical education classes with at least $50 \%$ of class time spent being physically active.) As the findings suggest, there is an ongoing need to strengthen physical education programs to favorably impact the health of children and adults. This can be done by emphasizing lifelong physical activities that enhance health-related fitness and providing students with the knowledge, attitudes, motor skills, and behavioral skills they need to adopt an active lifestyle that will persist throughout their lifetime (CDC, 1997). However, as the findings also reflected, the opportunity to impact the health of children and adults through school physical education programs was in jeopardy due to low and declining levels of participation in school physical education classes among U.S. high school students.

The findings from the YRBSS (CDC, 1997) emerged at a time when many national organizations had expressed concern about the quantity and quality of school physical education programs, and were urging state and local education agencies to implement daily physical education classes for all students in kindergarten through 12th 
grade. The organizations were also urging these education agencies to provide students with an opportunity to be active in physical education class in ways that emphasize lifelong health-related physical activity goals (rather than competitive sport-related skills) (Lowry, Wechsler, Kann, \& Collins, 2001). As reported by Lowry et al. (2001), national health objectives were established for the year 2000 that called for: (a) increasing to at least $50 \%$ the proportion of children and adolescents in grades 1 through 12 who participate in daily school physical education (objective 1.8 ; baseline $36 \%$ in 1984-86) and (b) increasing to at least $50 \%$ the proportion of school physical education class time spent being physically active, preferably engaged in lifetime physical activities (objective 1.9). These objectives were intended to assure that students were provided with the opportunity for a substantial proportion of the moderate and vigorous physical activity recommended for adolescents while learning physical activity strategies and activities that could be continued into adulthood (Sallis \& Patrick, 1994; USDHSS, 1996). However, as suggested by Lowry et al., the YRBSS findings offered little hope that the 2000 national health objectives would be met. Most importantly, as reported by the researchers, the CDC report demonstrated the need for the commitment of communities, teachers and school officials to strengthen their efforts to insure that quality daily physical education was offered to all students.

Developmental Process: Learning Fundamental Movement Skills For many years, the emphasis in fundamental movement education has been on product, not process. Games and playful activities have taken precedence over physical activities that, based on individual developmental levels of the individual, emphasize the acquisition of those sequential movement skills and methods that increase physical 
competency. As evidence has suggested, the assumption that mature levels of fundamental movement skills develop independently of instruction is not valid (Gallahue \& Ozmun, 1995). The National Association for Sport and Physical Education (NASPE) has assumed a major role in the establishment of guidelines and standards for developmental physical education. The goal of such standards and guidelines is to develop a wide variety of appropriate practices to promote movement skill acquisition and increase individually appropriate physical competence (NASPE, 1995c).

Developmental physical education has been identified as an educational framework that has utility in the promotion of developmentally appropriate movement skill acquisition and physical competence. This framework is based on recognition of the uniqueness of the individual in the implementation of individually appropriate instruction. The fundamental premise of this approach is that while motor development is age related, it is not age dependent (NASPE, 1992). Consequently, decisions made by the teacher concerning what to teach, when to teach it, and how to teach include, but are not limited to, consideration of the appropriateness of the activity for a certain age group (NASPE, 1995b).

The selection and effective application of appropriate physical activities for children requires knowledge and an understanding of the components of movement classification and acquisition. As explained by Gallahue and Ozmun (1995), movement skills are acquired by progressing through phases and stages, from infancy through adolescence. In addition, movement skills are subdivided into three categories of underlying components including locomotor, manipulation, and stability. Within each category are movement skill themes such as walking, throwing, bending, and dodging 
that dictate appropriate selectivity of movement for each skill development activity. A similar approach to teaching skill development through skill themes and movement concepts is a system reference called "the wheel" (Graham, Holt/Hale, \& Parker, 1996). The wheel system reinforces a common learning process approach to movement acquisition. An example of the approach is the interaction between skill themes and movement concepts. This interaction is useful for refining such skills as catching, striking, volleying, and balancing appropriately for specific education grades.

The wheel concept reinforces the need for movement education to focus on the areas of movement skills; force, relationships, and spatial awareness. Movement competency in these three areas is essential for learners to move into more complex or specialized movernent such as sport skills.

The acquisition of movement skills in phases and stages begins during infancy, as children pass through the reflexive movement phase and the rudimentary movement phase. Involuntary movements for the infant are eventually overtaken by cognitive processes that allow voluntary motor control in such things as grasping, crawling and basic walking.

The fundamental movement phase occurs from ages two to seven. Ideally, at this age, children should master basic locomotor, manipulative and stability skills during a continuum of stages within this phase, progressing from the initial, to the elementary, then to the mature stage. The initial phase of movements at age two, such as crude uncoordinated catching, throwing, and jumping generally develop into well coordinated, mechanically correct, efficient acts that are appropriate to the mature stage demands of the task at age seven. From age seven to ten, children are typically at the specialized 
movement phase of development. At the specialized phase, fundamental movements within the locomotor, manipulative, and stability categories are combined, refined and applied to a wide variety of more complex movement tasks as experienced in sport skills.

The specialized movement phase, therefore, is the appropriate age to develop any given type of movement task in the physical education setting. Critical to the learning process are the specific requirements of the task. As well, recognition must be given to the fact that during this phase the biology of the individual and the condition of the environment interact to determine the rate and extent of the development in the motor domain (Gallahue, 1997).

An important consideration in efforts to assist children in learning a new movement skill is the hierarchical nature of sequential progression learning. This process of learning has been classified into broad levels and sub-stages (Gallahue \& Ozmun, 1995; Magill, 1993). As the child moves through these levels and associated sub-stages, learning occurs sequentially. Thus, attainment of skill at each level prepares the child for the next level. Teachers can help to maximize learning by being aware of where the child is in the learning process, the skills the child has grasped, and determining how he or she can be best assisted to move forward sequentially.

According to Magill (1993), the process of learning a new movement skill is the same regardless of the age of the learner. The process occurs as one develops a general awareness of the skill and what is involved in performing the skill. Subsequently, efforts are made to explore the essential elements associated with performing the skill. After moving through this process and through systematic inquiry, the individual discovers how to apply and be successful with the skill. Continual practice assists in further 
utilization of the skill, allowing for the skill to become more refined so that individuals can reach a level of personal performance that meets their needs and interests.

An important component of any educational program is assessment or progress evaluation of movement competency and proficiencies. In comparison, product-oriented curriculums are concerned only with the end-performance outcomes whereas, process oriented curricula are concerned with the form, style and/or mechanics used to perform a movement skill. In traditional Practice Style methods of teaching, drills and practices of skill focus on the product of the act. In focusing on the process associated with movement acquisition, the teacher is primarily concerned with the body mechanics used to engage in the skill. As explained by Gallahue (1997), when the primary goal is to teach children how to move, the concern for proper body mechanics or the process of movement must occur before focusing on the product. Children should learn what it takes to make a successful lay up shot in basketball before they are asked to simply shoot as many baskets as they can.

The developmental framework for physical education programming utilizes a movement skill theme approach as the primary vehicle for promoting skill acquisition. A movement skill theme is a series of activities that focus on one or more related movement skills that are both age group and individually developmentally appropriate for a child. In the application of this approach, the objective is to develop skillful, knowledge-based and expressive moves, rather than focusing on an isolated content area (e.g., games, dance or self-testing activities.) An isolated content focus is often used within traditionally based physical education or movement education curriculum. An example of such a focus is exemplified within the utilization of "the wheel" in which a movement 
concept (e.g., effort, space or relationships) becomes the basis upon which instruction occurs. Alternatively, movement skill themes center on specific movement skills that are to be developed and refined as a major focus in lesson implementation. Examples of a movement skill thematic approach include instruction on shooting a basketball from a right- hand lay-up or hopping off one foot (Gabbard, LeBlanc, \& Lowy, 1987; Graham et al., 1996).

In summary, the emphasis in physical education skill acquisition has been changing from product to process. While an educational focus on movement process has roots in the past, traditional approaches to physical education lessons have not as of yet been curtailed. When focusing on movement processes, concern is directed toward the level of the child's ability (as based on developmental appropriateness) and the specific needs of the children to receive appropriate information in a manner that will help them internalize it. Concern is also directed toward meeting the teachers' needs that include teaching when they lack appropriate instructional equipment and providing sufficient instruction time. Most importantly, concern is directed toward developing a curriculum with an emphasis on body mechanics.

\section{Curriculum Strategies to Enhance Learning in Physical Education}

In the process of helping students learn, pedagogical content knowledge (PCK) is essential for teachers and coaches (Griffin, Dodds, \& Rovegno, 1996). PCK includes an understanding of the learners, the activity, the physical education program goals, the instructional strategy, and the students. As suggested by Griffin et al. (1996), teachers and coaches with a solid understanding in the application of PCK become highly successful. This is due to their knowledge of how to integrate key elements of effective 
instruction including variation in teaching practices. These key elements are providing corrective feedback and cueing, incorporating object free movement, facilitating movement progression, organizing students effectively, and arranging optimal lengths of practice time. Each of these key elements will now be reviewed.

\section{Variation in Teaching Practices}

Since teaching influences learning, physical educators spend much of their time planning, carrying out, and evaluating instruction. Decisions and concerns associated with these tasks include those related to organization of activities, organization of daily lesson plans, provision of the most effective instructions, and utilization of effective feedback. Such decisions impact the learning environment as well as knowledge and skill acquisition. Thus, improved learning outcomes are associated with a teacher's ability to create an appropriate learning environment for students. As Magill (1990) explained, research and experiments typically engage subjects individually and fail to focus on class-setting concerns. Therefore, teachers do not always have the types of knowledge necessary for developing effective learning environments within classroom settings. Magill (1990), has explained that issues of teacher feedback, organization of practice, and length and spacing of practice remain critical to the teaching approach of skill learning.

\section{Corrective Feedback and Cueing}

An important decision faced by teachers in every teaching setting is how much and when should feedback be given. When teaching a complex skill, the difficulty that lies in a practice lesson is in determining when to give feedback by observing various cues to the movement. In a traditional setting of practice, at any given moment numerous 
students are performing different aspects of a complex skill such as shooting a basketball. Consequently, it is difficult for one teacher to give individual feedback.

In spite of the difficulty associated with providing individual feedback, research findings have emphasized feedback as critical to skill acquisition. On the basis of a study conducted by Rikard (1992), the importance of immediate, specific, and corrective feedback in efforts to assist students in skill acquisition, especially for low-skilled students, was evidenced. Similarly, Graham and Heimerer (1981) found in their processproduct research efforts that less effective instruction resulted from teachers who responded as low reactors with neutral feedback. Researchers (i.e., Graham \& Heimerer, 1981) have also reported that high reacting teachers were more effective teachers who gave specific feedback during the process. On the basis of these findings, it was recommended by Graham and Heimerer that learning activities be structured in such a way that all students perform simultaneously, lending more opportunity for teachers to observe and provide necessary and specific feedback.

In a study of one of the components of feedback, Masser (1993) investigated "critical cues". He found that when a group that had received one or two critical cues while learning a fundamental motor skill that there was a significant positive effect and that they were able to maintain improvement over a period of 3 months. There was not significant improvement in a no-cue group or a control group. A group receiving 4 or 5 critical cues improved, but did not maintain the high level of performance after 2 months. Clearly, for cueing to be an effective instructional strategy, its use must be appropriate.

Therefore, theoretically a more effective approach for effective feedback compared to Practice Style would be to arrange students in a whole group moving 
simultaneously during the skill practice. This would allow for teachers to observe students performing each movement of the skill and provide timely individual, specific, and corrective feedback during the task.

\section{Object Free Movement}

Another relevant issue related to skill acquisition is control of object. As suggested within the literature, lack of object control may be a primary reason studies have not been able to demonstrate change in many strategy and skill variables (Rink et al., 1996; Turner \& Martinek, 1992). Since most complex sports require the ability to produce force, less skilled students found themselves on the receiving end of the force and found it difficult to learn the manipulative skills needed to develop the complex skills necessary to participate in the activity (Graham, Ellis, Williams, Kwak, \& Werner, 1996). According to Rink et al. (1996), the tendency in physical education programs, even elementary programs, is to put a major emphasis on accuracy in manipulative skills without taking into consideration that a child who is fearful of being hit with a ball will have trouble learning how to manipulate that ball and pass it on. This child will have trouble producing the force necessary to participate in the activity. A more appropriate emphasis is probably to help students learn how to use their total bodies with and without implements to more successfully produce and reduce force. (Rink et al., 1996).

The influence of a child's inadequacy of skill ability on performance outcomes has been identified as another factor supportive of teaching movement control before object control (McKiddie \& Maynard, 1997). According to Roberts (1984), evidence suggests that the correlation of children's self perceived physical competence and their actual physical competence increases positively as children get older. Findings by Stipek 
and McIver (1989) and Abound (1985) help to explain why this may be the case. As indicated by these researchers, on the basis of their research findings, important developmental change occurs at age 12 or 13 , influencing levels of reasoning and understanding that ability is capacity and not merely performance. Ability, therefore can be influenced by skill acquisition, although children below this age may not understand this fact. For younger children, therefore, it is especially important that instruction for skill acquisition be through activities that they like. Similarly, Rudisill, Mahar, and Meaney (1993) reported that at approximately 12 years of age children are competent at combining all the information in motor-skill lessons into an accurate appraisal concerning their competency. As suggested by the researchers (i.e., Rudisill et al., 1993), children at this age have reached the operational stage of cognitive development and are able to solve problems, unlike most children ages 9 to 11. Thus, for most 12-year-olds, all information relating to former and recent assessments of performance can be used to evaluate personal competence.

Beginning at this age they can understand that a refinement is necessary to be more successful with their physical skills and they are more likely to want to practice in a different fashion in order to be successful, competent and competitive. They will take more time to methodically think out the necessary sequential movements to something like shooting a basketball. At this age they will go through the movements of several trial attempts at a jump shot in order to fine-tune their movements before they get the ball. They have more sensory perception of what their kinesthetic movement is than younger children do. Therefore, having reached this maturation point, most 12 year olds 
are able to find object free movement valuable and they are more likely to be successful at it.

Results of the aforementioned studies suggest using object free movements during skill acquisition practices. Conceptually a method of teaching that promotes students' awareness of movement relationships to skill performance may increase skill acquisition. For example, repeatedly positioning the arms to shoot a basketball while thinking about that position develops an understanding of what they need to do to be successful as well as conditioning the motor process of shooting the basketball toward the goal. Once that understanding and conditioning have been attained through object free practicing, the implement (the basketball) is provided for continued practice that will lead to the desired observable outcome - a successful basket.

\section{Movement Progression}

One of the challenges facing physical education instructors is how to structure lessons and practices in order to encourage movement progression. As Rink, French, Werner, Lynn, and Mays (1992) explained, a number of decisions must be made in response to this challenge, including determining the practice conditions, focusing on that practice and the movement on which the practice content is developed, and the process by which a high number of correct practice trials can be encouraged. The literature on movement progression in relation to effective teaching in physical education points out the need for a creative instructional environment that increases the number of correct trials for the student (Rikard, 1991, 1992; Silverman, 1993). In determining the manner in which to interpret a correct trial, as defined by Siedentop (1991), success can best be 
understood as about an $80 \%$ probability of doing the task correctly as defined in the lesson.

Buck, Harrison, and Bryce (1990) studied the effects of different learning environments on four volleyball skills with a college beginners' volleyball class. The result of the study indicated that total correct trials were the only significant factor in determining the rate of learning for the skills. When the average trials per day, per student, were very low, the average correct and total trials per day indicated a lack of practice for each individual component skill. The more complex skills (spike, serve) showed the least improvement for all groups (i.e., low-skilled, medium-skilled, highskilled). Interestingly, the low-skilled students who attempted fewer correct trials to total trials had lower learning ratios. They indicated that there need to be enough trials to have many correct trials of individual component skills as well as enough trials of the complex skill. Aligning a developmental approach to content is a pedagogical concern that has received considerable attention. Teachers most frequently attempt to blend content progressions (extensions), self-testing movement (application) and proper mechanics to practice quality without changing task complexity (refinement). On the basis of the findings from a study conducted by Buck et al. (1990), the researchers recommended that students of all abilities and developmental levels have more trials. In addition, many more trials per day are required to learn complex skills that require coordination and timing, especially if the skills are to be incorporated into game or drill competitive activities. Justification for practice progression to enhance correct trials and therefore skill acquisition has been supported by and evidenced within other research (e.g., Rink, 1986; Tyler, 1949; Vogel \& Seefeldt, 1988.) 
The findings from these studies provide further evidence for the need to advocate for instructional experiences for learners designed to present progression of content that vary from simple to complex, with the basic assumption that beginning levels of skill needed to be mastered before more complex versions are presented. Children must learn fundamental movements first in order to acquire more complex skills. To hit a softball tossed to them they must first be able to successfully track the ball, swing the bat and hit the ball. They should learn to successfully track the ball and to swing properly, at waist height, before they attempt swinging with a bat. If they are given sufficient opportunities to succeed at trials of each of the component skills, they will need fewer total trials of hitting the ball to achieve success.

As well, Rink (1986) identified that extension tasks that change the conditions of the previous task to either reduce or increase the task's complexity for the learner is essential for learning sub-skills prior to introducing more complex skills. According to Werner and Rink (1989), the teacher can manipulate practice conditions that support progression learning in many ways. One way is by using a progression of parts. Another is by modifying equipment. A third, by changing things such as the spatial relationships for practice, the intent of the skills, the number of people involved, or the number of repetitions of the same skill. Practice conditions can also be manipulated by sequencing the practice of one skill with another skill.

Schmidt (1975) also supported movement progression by suggesting varying initial conditions, such as employing variations of approaches to practice and intent of the movement, that may enhance the recall schema involved in movement progression. Schmidt (1975) postulates providing alternative practice opportunities that afford the 
leamer experience at appropriate levels of task difficulty and varying the conditions to produce effortful practice may help to resolve difficulties in developing instruction to teach complex tasks. As well, in further consideration of processes that aid movement progression, Rink et al. (1992) hypothesized that the nature of progression relative to specific content and self-testing will help to further facilitate and influence the acquisition of motor skills in physical education activities and settings. As suggested by Rink et al. (1992), motor skill acquisition for students of all abilities and developmental levels is best achieved in a setting that facilitates learning in a self-testing manner.

An experimental teaching method utilizing movement progression through a stepby-step procedure combined with other strategies may increase skill acquisition. For example, planning practices that promote simple-to-complex stages of development while providing multiple successful trials for all learning abilities may improve individual achievement. Basketball shooting development footwork movements would be the first phase of learning the shooting skill. Practicing placing the non-shooting foot is the first movement in the step-by-step procedure of the shooting skill. The second step is placing the shooting foot correctly. Once these steps have been successfully demonstrated, the student then proceeds to the second phase. This phased developmental process continues until the entire skill of shooting a basket has been learned. Research has shown the efficacy of this method with students who have a wide variety of initial skill levels (Rink et al., 1992).

\section{Group Organization}

A key component identified with organization of practice is grouping. Grouping is a dimension that is used to describe whether teachers work with an entire class, large 
groups, small groups, individuals, or combinations of these groups (Anderson \& Scott, 1978). Medley (1979) found that overall, more effective teachers spend more time working with large groups and the whole class than they do with small groups and individuals. McDonald (1976) suggested that whole class instruction was more effective when teaching a new process. Once the process was taught, however, individualized instruction with close monitoring seemed to be more effective. Traditionally, physical educators have mostly used an individual student performance approach that is a characteristic of drill and practice lessons.

This is the common practice, despite the fact that Hastie found in 1996 that student comments were negative about having to wait for turns to play or participate in practice during physical activity. He found that increasing desire for participation was linked to minimizing idle roles or activity in physical education. Whole group organization during activities chosen to help children internalize information about the body mechanics necessary for skill acquisition may reduce students' negative attitude toward physical education.

The degree to which students express preferences for certain activities has also been found to be a key component in the organization of practice. McKenzie, Alcaraz, and Sallis (1994) examined the degree to which students reported "liking" a physical activity within a physical education curriculum. Their research was conducted through evaluation of the Spark Project. The Spark Project was implemented in two elementary schools with 242 students in fourth and fifth grade classes, assessing 648 different physical education classes. The goal of the program was to engage positive feelings in the student toward physical activity by providing positive student-teacher interaction, 
high success rates, and limited group competition. Students were to rate the activities they enjoyed from skilled-related activities (basketball, soccer, and softball) and healthrelated activities (aerobics fitness circuits, running programs, and dance aerobics). Even though the health-related curriculum was generally liked least, aerobic dance received better ratings when designed with novelty. On the basis of the findings of the study, the researchers emphasized that specific activities need to be considered carefully when designing a physical education curriculum. More importantly, as suggested by the researchers, if methods could be developed for combining sports and aerobics, children may find physical activity more appealing, which may positively influence performance related outcomes. Also, as with new process instruction in sports, aerobics are best taught through whole class instruction.

Additionally, evidence has suggested that the degree to which physical activities facilitate physical outcomes is another important issue associated with organization of practice. With this factor in mind, Alpert, Field, Goldstein, and Perry (1990) investigated aerobic activity effects on agility, fitness, and self-esteem. A thirty-minute aerobic-dance activity was conducted five days a week for eight weeks. Based on their findings, the researchers recommend that a pre-school aerobic curriculum was a cost-effective forum of intervention for facilitating cardiovascular fitness and gross-motor skills.

In conclusion, the research suggests that an effective approach to group organization in an experimental method of teaching would be to have whole group formation during the initial stages of learning the basic skills. They suggest that whole group formation would create greater opportunities for the teacher to provide specific 
feedback, increase student participation, increase student confidence, and improve class management to facilitate task compliance.

\section{Length of Practice Time}

Rink, French, and Tjeerdsma (1996) reported that numerous physical education studies have been unable to demonstrate any significant difference or change from pre to posttest scores for skill acquisition. In many cases, there was no significant difference for other dependent variables as well. Rink et al, (1996) indicated that those short term studies may not have been conducted for a long enough period of time for any learning to occur. In a short term study, the expectation that students can develop enough knowledge to perform complex skills or enough skill in any instructional intervention to use complex motor skills is unrealistic given the number of lessons. Based on the study by Rink et al. (1996), those studies that did not show significant difference or change conducted nine classes or less. French et al. (1996) also used a 15-lesson study to measure skill acquisition for four badminton skills with ninth graders. The studies from Turner and Martinek (1995b), McPherson (1992), and McPherson and French (1991) all showed improvement with 15 classes of 30-minute duration for grades six and seven.

Spacing of time guidelines, according to Magill (1990), favors shorter lengths of practice time per class or practice session to longer periods of practice time per class or session. For example, a study published by Baddeley and Longman (1978) compared a one-hour motor skill training session per day for 12 weeks, to a two-hour session per day for six weeks. The results indicated the shorter practice sessions over a longer time period provided greater results. Magill (1990) indicated that adherence to this guideline (i.e., less duration over a longer period of time) will vary according to the skills being 
taught and the class or practice session. Braddeley et al. (1978) also suggested that implementing individual practice time was preferable to increasing the duration of the class period to increase motor skill development. Thus, a unit plan of 15 lessons for 30 minutes each, conducted twice a week along with individual practice time, should provide sufficient training time for grade five students learning three skills.

\section{Internalization}

The actual learning of the new movement skill is an internal process that can be observed only indirectly through the product of one's movement. Learning is a process that frequently occurs within the individual through reconstruction of incorrect mastery attempts (attempts to perform a perceived correct movement of a skill.) As one moves from an uncoordinated and poorly controlled attempt to perform movement that one has seen demonstrated or heard described to a highly refined, coordinated, controlled performance, the process of learning is occurring. This transformational process eventually results in the finished product: movement performance.

"Practice allows the performer to develop a central representation or motor program for the movement. As the representation becomes more developed it begins to control the movement in the absence of peripheral feedback" (Coull, Tremblay, \& Elliott, 2001, p. 345).

In contrast others have argued that the process of internalization begins with people sensing what their own bodies are doing. For those who follow this alternative understanding of internalization, the importance of sensory information increases with practice (Adams, 1971; Elliot, Chuo, Pollack, \& Lyons, 1995). Thus, skill acquisition actually involves learning to use various sources of sensory information more effectively 
in order to transform the information into movement performance. In this alternative view of internalization, there is greater recognition that children use tactile and kinesthetic (bodily) senses as avenues for learning in addition to the visual and auditory modes. Sport Aerobics is based on this second understanding of the process of internalization.

\section{Conceptual Framework for Skill Acquisition}

The focus of Sport Aerobics is the refinement of muscle mechanics so that complex skill acquisition may be developed in an orderly sequenced method. In contrast, the focus of Practice Style is on the whole movement of the complex skill. Without a focus on refinement, children are given the ball and expected to take the entire movement and produce something. Without instruction in the process, they're supposed to know how to go through the sequences to develop the whole. A step by step approach to the process of learning from simple to complex movements is considered too time consuming for Practice Style methods. With this method, this would take a lot of time because each child would have to have a basketball and would have to wait in line to practice each submovement in turn. With Sport Aerobics, strategies such as movement progression are considered important and are accomplished in a timely manner. With this method, the children are taking one stage at a time and refining it before going to the next stage. There is no lag time, however because they are not waiting in line, they are moving simultaneously. Time is spent on continuous sequential movement rather than on chasing the basketball all over the place.

In Practice Style instruction, feedback is often intermittent and done at opportunistic situations. Sport Aerobic uses immediate feedback with specific cueing. 
The cueing sets up each of the stages so students can identify with each of the muscles and positions of the muscles for the mechanics. Immediate feedback, including specific cueing by the teacher facilitates and reinforces immediate and continual corrective learner responses and adjustments to skill mechanics and movements.

Object free movement, another element of Sport Aerobics, allows learners to focus primarily on their body mechanics. This helps muscle memory processing, while eliminating difficulties associated with premature (or "too soon"?) basketball manipulation. They can focus on their movement orientation better because they are not distracted by having to also manipulate and control the basketball. Learners must do all of these things at the same time in Practice Style instruction.

Sport Aerobics organizes all the learners into one group, as opposed to Practice Style's various independent groups. This is done in Sport Aerobics to facilitate direct instruction and simultaneous responses. Learners are all together and doing the same thing. This means that teachers know that learners are all taking one stage of a complex skill at a time and refining it together. It also puts teachers in close proximity to learners. Both help teachers with providing effective feedback.

The literature supports Sport Aerobic strategies as effective for skill acquisition. Some things, such as the curriculum and the timing of physical education classes are outside the teacher's control. This study focuses on something the physical education teacher does control, the instruction strategies. It compares the outcomes of two groups of fifth grade basketball classes on shooting, dribbling, and passing skill acquisition. The conceptual framework is presented in Figure 1. 

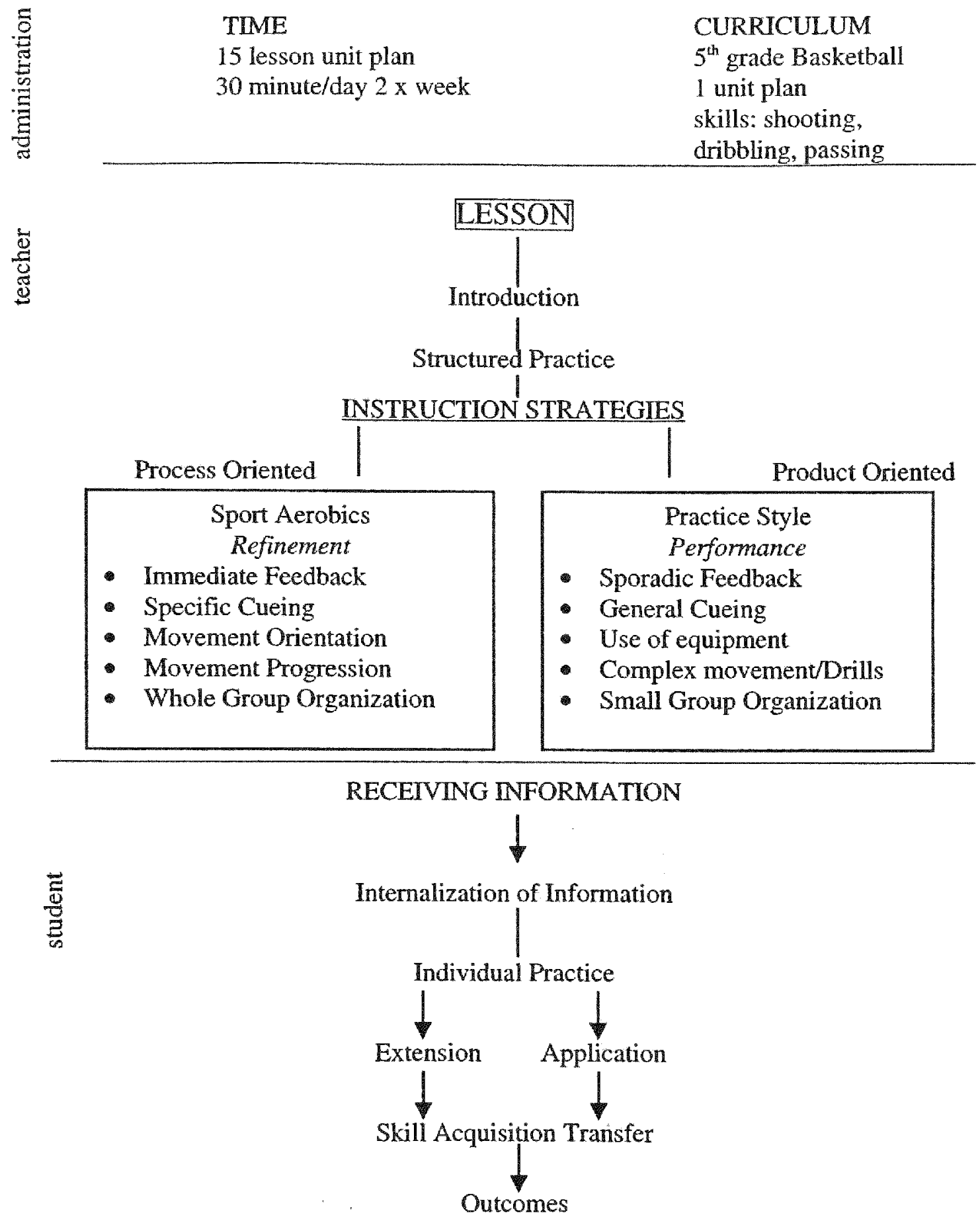

Figure 1. Conceptual framework for skill acquisition. 
On the basis of the information in the literature review, and this conceptual framework, a comparison may be made of the Sport Aerobic teaching method and that of the Practice Style method, as shown following in Table 1. Their differences in student organization, focus of the curriculum and instructional strategies may be clearly seen here.

Table 1

Comparison of Variables of Practice Style and Sport Aerobics Models of Learning

\begin{tabular}{|c|c|c|}
\hline Variables & Practice Style Model & Sport Aerobics Style Model \\
\hline Organization of class & $\begin{array}{l}\text { Multiple groups. } \\
\text { Learners move } \\
\text { independently. }\end{array}$ & $\begin{array}{l}\text { Whole groups. } \\
\text { Learners move } \\
\text { simultaneously. }\end{array}$ \\
\hline Feedback and Cueing & $\begin{array}{l}\text { Teacher offers while in } \\
\text { close proximity to some } \\
\text { learners. } \\
\text { Students may or may not be } \\
\text { engaged in task during } \\
\text { feedback. }\end{array}$ & $\begin{array}{l}\text { Teacher offers while in } \\
\text { close proximity to all } \\
\text { learners. } \\
\text { Students continually } \\
\text { engaged in task during } \\
\text { feedback. }\end{array}$ \\
\hline Movement Progression & $\begin{array}{l}\text { Learner in self directed } \\
\text { movement learning. } \\
\text { Complexity of skill } \\
\text { experienced as a whole. }\end{array}$ & $\begin{array}{l}\text { Learner's movement } \\
\text { response is directly related } \\
\text { to teacher's command. } \\
\text { Movement learned step by } \\
\text { step by step, simple to } \\
\text { complex. }\end{array}$ \\
\hline Movement Orientation & $\begin{array}{l}\text { Teaching strategy changes } \\
\text { from subject centered to } \\
\text { performance centered in } \\
\text { each class period. } \\
\text { Proficiency of movement } \\
\text { leamed from practice with } \\
\text { implements (basketball / } \\
\text { baskets). } \\
\text { Focus on performance and } \\
\text { knowledge of results. }\end{array}$ & $\begin{array}{l}\text { Teaching strategy } \\
\text { continuously student } \\
\text { centered. } \\
\text { Proficiency of movement } \\
\text { learned from practice } \\
\text { without implements. } \\
\text { Focus on mechanics and } \\
\text { steps of movement. }\end{array}$ \\
\hline
\end{tabular}




\section{Summary of the Chapter}

Traditionally, a limited number of class periods, semester scheduling, varying levels of student abilities in a single class, inadequate feedback and cueing, poor organization of activities, lack of attention to developing movement complexity and lack of object control have all contributed to minimizing the leaming process. As evidenced within the literature review, however, teaching motor-skill development requires a focus on process rather than product. Also, as was documented within the literature, a fundamental proposition associated with a developmental perspective is that motor development is age-related, not age-dependent and includes consideration of a variety of factors in planning and implementing lessons. A case was made in the literature that appropriate learning activities and settings for developing body mechanics need to be addressed for all levels of abilities/levels. 


\section{CHAPTER III}

\section{METHOD}

In this chapter, the research design will be presented, followed by a discussion of the research methods and procedures employed within the study. Included in the discussion will be the following: the selection of study participants, the experimental and comparison group treatment conditions and the manner in which each condition was implemented during the study, identification of the study variables measurements, and the instrument of measurement. A discussion will then be provided on the data collection and data analyses procedures utilized.

The purpose of the study was to investigate the effect of physical education teaching instruction of basketball skills utilizing a Sport Aerobic instruction strategy, which is a developmental technique, on the shooting, dribbling, and passing improvement of fifth graders. The research design, procedures and methods of data analysis were selected to best accomplish this purpose and to address the research questions underlying the study. The research questions were as follows:

1. Do differences exist between the basketball shooting scores of children who received Sports Aerobics instruction, using a combination of techniques including object free movement, movement progression, immediate feedback, specific cueing, and simultaneous group organization, as compared to the scores of those children who received Practice Style Basketball instruction lessons?

2. Do differences exist between the basketball dribbling scores of children who received Sports Aerobics instruction, using a combination of techniques including object free movement, movement progression, immediate feedback, specific cueing, and simultaneous group organization, as compared to the scores of those children who received Practice Style Basketball instruction lessons? 
3. Do differences exist between the basketball passing scores of children who received Sports Aerobics instruction, using a combination of techniques including object free movement, movement progression, immediate feedback, specific cueing, and simultaneous group organization, as compared to the scores of those children who received Practice Style Basketball instruction lessons?

\section{Research Design}

The research design for this study was a pretest-posttest nonequivalent group design with two treatment groups (Kirk, 1995).

As explained by Gribbons and Herman (1997), one of the major problems identified with the use of the nonequivalent groups design is that the researcher cannot insure that the two groups are necessarily the same prior to the administration of the treatment/instruction under investigation, as random assignment did not occur. The groups may in fact differ in important ways that influence the study outcomes. However, as explained by the authors, through the inclusion of the pretest-posttest component within the design, this major limitation is partially eliminated.

In light of this and other issues representing threats to internal validity, recommendations have been made regarding the use of quasi-experimental designs in order to control for design flaws. As suggested by Gribbons and Herman (1997), data obtained from studies in which quasi-experimental designs have been employed should be augmented by rich descriptions of programs and mechanisms used within the study. As stressed by Cook and Campbell (1979), it is always critical that the researcher consider alternative explanations for any observed differences in outcome measures. If the treatment group outperforms the control group, the researcher should consider a full 
range of plausible explanations in addition to the claim that the innovative practice is more effective.

\section{Participants}

Within this section of Chapter Three, a description of the study sample will be provided. Also, specific procedures implemented within the study will be delineated, including an explanation of the process and manner in which the experimental and comparison conditions under investigation were delivered, measured, and data collected.

The study was carried out at two sites. The first site, an elementary school with 1200 students selected from a large multi school district enrolling 100,000 students in a suburb of a southeastern city. The racial composition of the student body was approximately one-third Black, one-third Hispanic and one-third Caucasian. The second site was a summer school with 800 students, offered by the University of Miami with approximately the same racial/ethnic makeup.

Student demographics for both sites were found to be similar. All students of both the school and summer school were of similar characteristics and physical education experience. The students in the elementary school and in the university summer school were both boys and girls aged 10 to 11 years. The students in both groups had had similar physical education activities and programming ( 2 days/week in $30-40$ minute classes). For 9 weeks the University of Miami's summer school curriculum was similar to the public elementary curriculum, both using the same standard school district goals and objectives. Similar courses in both included art, music, cooking, special events, physical education, free time, and lunch. 
Fifth graders were targeted for inclusion in the study since physical education activities at this grade stress sport skill acquisition objectives and goals. While random selection of study individual participants was not possible, intact classes from the elementary school and summer school were randomly assigned the experimental and comparison condition. Moming midweek classes were selected (Tuesday, Thursday, 9:00 -9:30 a.m. and 10:00 - 10:30 a.m.) Selecting the midweek classes avoided weekend early dismissals, and selecting early morning classes avoided afternoon weather conditions of heat and humidity. One class for each treatment was selected from each of the two programs. Additionally, a coin was flipped in order to decide treatment assignments. The 9:00 a.m. classes were assigned the experimental Sport Aerobics treatment at both sites. The 10:00 a.m. classes were assigned the comparison Practice Style treatment. Each class consisted of approximately $20-25$ students of approximately equal numbers of boys and girls. A total of 79 students participated in the study.

While 90 students started the study, due to missed posttests or excessive missed classes (more than one class missed per skill), 79 completed the instructional unit. Prior to beginning participation in the study, parents signed a release giving permission for the child to participate in the study (Appendix $H$ ). One hundred percent of the permission slips were returned.

One teacher was chosen from each site for this study. The teachers for the study had similar teaching physical education experience (including a minimum of 3 years work in a school setting and instructing both Practice Style and Sport Aerobics.) Both teachers participated in identical training to prepare them for teaching the methods under investigation within the study. The teachers of the selected classes taught both groups at 
their site, including the experimental and comparison groups, in order to control for teacher differences.

The teachers were also trained to use the basketball test battery. In addition, a qualified certifying instructor gave both teachers training materials (video and workbook) and a hands-on training workshop. The workshop consisted of 8 hours of training, split into two 4-hour sessions to allow study and practice time. The teachers were given lesson plan outlines with special skills, cues, activities, and pre/post tests for both study conditions so instructional approaches and content were consistent for the duration of the physical education program under investigation (Appendices D \& E).

\section{Procedures}

As the purpose of the study was to investigate the effect of physical education teaching instruction of basketball skills utilizing a Sport Aerobics instruction strategy, Sport Aerobics was implemented in the physical education curriculum of each of the schools' Tuesday/Thursday 9:00 a.m. classes while the Tuesday/Thursday 10 a.m. classes received the Practice Style treatment. Following is a description of the two treatments implemented in the study.

\section{Sport Aerobics}

Before the lessons began, students were given a presentation and demonstration of Sport Aerobics through a video, 20 minutes in length, in which children, ages 9-13, demonstrate the Sport Aerobics workout with accompanying athletes performing correlating sport participation. The video workout was segmented into warm-up (consisting of various general sport movements and stretches, relating to general sport 
range of motion), workout basketball segment (consisting of specific skills to be tested), and cool-down segment (similar to the warm-up) with a final stretch segment offered.

The music used for Sport Aerobics was supplied to the teachers and was carefully selected to meet motivation pace, tempo, creativity of the activity, and age of the students. Successful pilot studies of the music and popularity of the music for this age group supported the use of the music for this project.

Lessons. The instructional strategies used by the teachers during each 30-minute lesson consisted of the following:

1. The teacher provided direct instruction for each lesson in sequence including introduction of skill (importance, application), execution of skill (live demonstration), verbal cues (preparation phase, execution phase, follow through phase), class practice (walk through cues), for approximately 10 minutes.

2. The teacher led the Sport Aerobic routine while students followed along in group formation for approximately 15 minutes without equipment.

A. Students repeated routine while teacher critiqued each student's skills.

B. Students orally expressed physical sensations associated with the targeted concepts and skills being taught in the context of the Sport Aerobic activity,

C. Teachers and students reviewed the lesson skills and movements.

3. Each student was allowed 5 minutes of practice time on a skill of their choice (any part of dribbling, shooting or passing) with the ball and basket.

Teacher training. The experimental group teacher participated in an 8 hour training session conducted by the researcher three weeks before the school semester or camp began. The content of the training was as follows: 
1. Overview of the research project.

2. Overview of the Sport Aerobics method and its rationale. This included (a) uses of music, (b) producing a creative environment,

(c) using verbal and visual cues, (d) establishing lines of communication,

(c) the physical execution of skills, and (f) making skills routine.

3. The process of basketball skills development. This included (a) moving from simple skills to complex ones, (b) developing a nurturing classroom climate, (c) promoting social interaction, (d) establishing and maintaining student involvement, (e) practicing with and without equipment, ( $f$ ) using the check list and block plan, and (f) time for review and discussion.

4. The use of direct instruction procedures. This included (a) the development of specific class objectives and their importance, (b) using direct instruction in learning activities, and (c) time for review and discussion.

5. Strategies for using testing materials to quantify the attainment of basketball skills.

The workshop also provided instructions for the teachers in collecting data for the study which included the treatment schedules (Appendix B), the keeping of information concerning student attendance and the reporting, and procedures for reporting the results of data gathering to the researcher (Appendices $\mathrm{C}$ and $\mathrm{F}$ ).

The treatment. The teacher taught each lesson for a block of one half-hour. The total duration of the experimental treatment was 15 total lessons (Appendix B). The first two and last two days were testing and introduction days. Teachers gave direct instruction progressively from simple to complex skills (Appendix D). This approach allowed fundamental development by students. First, students learned basic refinement by footwork in order to develop balance, change of direction, weight shift, coordination and force. Next, they learned basic set of body positions for basketball skills; the dribble, set shot, and passing was emphasized with each assigned class. 
After basic basketball skills were introduced and practiced, continual movement

within the basketball context during Sport Aerobics was implemented for each lesson.

Lastly, practice sessions with the equipment was added to the lesson sessions in conjunction with the experimental schedule. After each lesson review, questions from students were included if time permitted.

\section{Comparison Group}

The comparison group received Practice Style instruction in basketball. The following sections describe the comparison group treatment and the training given to teachers who worked with this group.

Lessons. The 30-minute Practice Style group basketball skill lessons consisted of the following:

1. The teacher provided direct instruction for each lesson in sequence including introduction of skill (importance, application), execution of skill (live demonstration), verbal cues (preparation phase, execution phase, follow through phase), class practice (walk through cues), for approximately 10 minutes.

2. The teacher led the students in drills and practice activities with equipment. Students were then guided by the teachers to summarize the lessons, skills, and movements for a total of approximately 15 minutes.

3. Each student was allowed 5 minutes of practice time on each skill of their choice (any part of dribbling, shooting, or passing) with the ball and basket.

Teacher training. The traditional group teacher were the same teachers as the ones who worked with the experimental group. Schedules, checklists, population information, scoring, and testing were all similar to those taught during the training for the experimental treatment. 
The treatment. The teacher taught the lessons for a one half-hour block, for a total of 15 lessons similar to the experimental group. The first two and last two days were introduction and testing days. The teacher gave direct instruction for each skill similar to the experimental group using the traditional methods of drills and activities with equipment. (Appendix E).

\section{Measurement}

The dependent variables were basketball skills (shooting, dribbling, and passing). The measurement of the basketball skills (shooting, dribbling and passing) was accomplished through the utilization of the American Alliance for Health Physical Education, Recreation and Dance Basketball Tests (AAHPERD, 1984) during pre and posttest measurements.

The AAHPERD test battery is applicable since Sport Aerobics is a continual movement activity developing student's speed, agility, coordination, and execution of specific fundamental basketball skills as shooting, dribbling, and passing. During pre and posttest measures, each independent skill test was scored based on the number of successful attempts in one minute (for shooting and passing) and the best time possible (dribbling). For example, the basketball dribble test measures the speed with which a player can dribble a ball around a predetermined course. The posttest time would be lower than the pretest times if the students improved their skill ability.

Instrument construction. A committee of five experts in the areas of basketball, measurement and evaluation representing college, high school and elementary grade levels was identified to develop the Basketball skills test manual at the time it was 
created during the $1970 \mathrm{~s}$ and $1980 \mathrm{~s}$. The development process of the measurement instrument included the completion of a comprehensive review of conceptual and skill-testing literature. In addition a survey of male and female basketball coaches representing professional, college, high school and elementary levels was conducted to substantiate the results of the literature review. Twelve skills test items were identified to measure the essential skills of shooting, dribbling and passing. A pilot study of the 12 experimental test items was conducted in the spring of 1980 in a school setting on samples of fifth and sixth grade students, including both boys and girls. The primary purpose of the pilot study was to determine the administrative feasibility of each test item. A secondary purpose was to provide preliminary estimates of reliability and validity.

Instrument reliability and validity. During the pilot study, reliability and validity coefficients for each test item for each sex and grade were established by the administration of the three-item battery in the school setting at the conclusion of a basketball unit (AHPERD, 1984). Fifty male and 50 female students in each of the two grades were administrated multiple trials of the test items. Test-retest estimates of reliability were found to range from $r=.87$ to $r=.95$.

Concurrent and construct estimates of validity were determined for the entire test battery. Concurrent validity evidence was obtained by comparing experts' subjective ratings of each skill with each of the three tests. For elementary school students these correlations were $r=.95$ for boys and $r=.81$ for girls. Construct validity evidence was obtained by comparing the performances on the tests of groups of varsity and non-varsity 
players. Varsity players scored significantly higher than non-varsity players at the .01 level of significance in all tests at all grade levels.

\section{Data Collection}

The study was conducted in the spring and summer of 2001. Data for the study were gathered at the time the scores for basketball shooting, passing and dribbling were obtained during the administration of the pre- and posttests. Pretest measurements were on the first day prior to the implementation of the experimental and comparison study conditions. Posttest measurements were taken on the day after the experimental and comparison conditions were terminated (Appendix F).

After the pre and posttests were administered, the tests for each student participating in the study were recorded. Finally, the scores of only those students who completed a consent form as well as the pre and posttest, and did not miss more than one class from each skill, were included in the study for analysis purposes.

\section{Data Analysis}

For analyses purposes, the scores obtained by study participants on basketball skills performances for both the experimental and comparison group were compared using an analysis of covariance (ANCOVA) with the respective pretests as covariates.

As explained by Trochim (1999), ANCOVA adjusts for disparities in covariates distributions over groups by artificially assuming that all groups have the same set of mean covariate values. For example, if age and weight are the covariates and there are two groups being compared, the ANCOVA adjustment procedure treats both groups as if they had the same mean age and the same mean weight. The ANCOVA adjustment procedure is equivalent to artificially assuming a common covariate distribution based on 
the combined sample over all group. That is, not only are the means assumed to be equal, but the entire distribution of the covariates in the combined sample is assumed to be the same as the distribution of the covariates in each group. Thus the method of adjustment using ANCOVA does what one hopes it will do: It corrects the disparity in covariate distributions over groups by assuming a common distribution.

Subsequently ANCOVA was conducted on each of the dependent variables: shooting, dribbling, passing. The pretest scores for each variable were used as the covariate to test for differences between group means of the adjusted variable posttest scores.

\section{Summary of the Chapter}

As noted, the research design employed within the study was a pretest-posttest nonequivalent-groups design. While random selection of study participants was not possible, random assignment of classes to the experimental and the comparison group conditions was implemented. For each of the study conditions, a detailed description was provided as to how each condition was implemented within the study. Also, the independent and dependent variables were identified and outcome measurement was explained. Information was also provided concerning the data collection phases of the study as well as the plan for data analyses. 


\section{CHAPTER IV}

\section{RESULTS}

The purpose of this chapter is to present the results of the effects of the Sport Aerobics teaching strategy compared to the Practice Style strategy on students' basketball skills (shooting, dribbling, passing). The findings and discussions are presented under the following headings.

Hypothesis 1: Results related to improvements in shooting.

Hypothesis 2: Results related to improvements in dribbling.

Hypothesis 3: Results related to improvements in passing.

$$
\text { Tests of Hypotheses }
$$

Tables 2 and 3 present the aggregate sample data for participants in the three sport skills.

Table 2

Descriptive Statistics for Students Using the Sport Aerobics Strategy

\begin{tabular}{lrrrrr}
\hline & \multicolumn{2}{c}{ Pretest } & & \multicolumn{2}{c}{ Posttest } \\
\cline { 2 - 3 } \cline { 5 - 6 } Skill & \multicolumn{1}{c}{$M$} & $S D$ & & $M$ & $S D$ \\
\hline Shooting & 8.71 & 4.58 & & 9.16 & 6.46 \\
Dribbling & 25.27 & 5.30 & & 22.30 & 3.01 \\
Passing & 29.58 & 7.52 & & 31.60 & 5.94 \\
\hline
\end{tabular}

${ }^{a} n=43$ for each skill

Table 3

Descriptive Statistics for Students using the Practice Style Strategy

\begin{tabular}{lccccc}
\hline & \multicolumn{2}{c}{ Pretest } & & \multicolumn{2}{c}{ Posttest } \\
\cline { 2 - 3 } \cline { 5 - 6 } Skill & $M$ & $S D$ & & $M$ & $S D$ \\
\hline Shooting & 5.31 & 2.71 & & 9.69 & 7.22 \\
Dribbling & 26.79 & 3.68 & & 21.93 & 4.96 \\
Passing & 27.39 & 5.91 & & 30.22 & 5.51 \\
\hline
\end{tabular}

${ }^{a} n=35$ for each skill 


\section{Hypothesis 1}

Students receiving Sport Aerobics instruction in basketball shooting will have higher adjusted posttest shooting scores than students receiving Practice Style instruction.

The corresponding null hypothesis that students receiving Sport Aerobics instruction in basketball shooting will have posttest shooting scores that are less than or equal to those of students receiving Practice Style instruction was tested.

The basketball shooting scores after an experimental Sport Aerobic basketball instruction strategy were compared to scores after a traditional Practice Style instruction strategy for Grade 5 students.

An analysis of covariance was conducted using the pretest shooting scores as the covariate to test for differences between group means of the adjusted shooting posttest scores. Table 4 shows the ANCOVA source table.

Table 4 Analysis of Covariance for Basketball Shooting

\begin{tabular}{lrccc}
\hline Source & $d f$ & $F$ & $\eta$ & $p$ \\
\hline${ }^{a}$ Shooting Score (Pretest) & 1 & 26.90 & .26 & $<.001$ \\
Strategy & 1 & $5.40^{*}$ & .06 & .01 \\
$\quad$ error & 74 & $(32.86)$ & & \\
\hline
\end{tabular}

Note: Values enclosed in parentheses represent mean square errors. ${ }^{*} p<.05$

${ }^{\natural}$ The covariate

The first null hypothesis is not rejected since the mean adjusted posttest shooting score for Sport Aerobic treatment group $\left(M_{a d j}=10.49\right)$ was significantly lower than the mean adjusted posttest score for shooting for the practice style treatment $\left(M_{a d j}=11.50\right)$, $\mathrm{F}(1,74)=5.40, p<.01$. The obvious conclusion is that although both groups improved from the pre-to the post-test, when groups were controlled for pretest differences, the 
Practice Style method was better than the Sports Aerobic method for teaching basketball shooting.

Hypothesis 2

Students receiving Sport Aerobics instruction in basketball dribbling will have lower adjusted posttest dribbling skills scores than students receiving Practice Style instruction.

The corresponding null hypothesis that students receiving Sport Aerobics instruction in basketball dribbling will have posttest shooting scores that are greater than or equal to those of students receiving Practice Style instruction was tested.

The effects of the two treatments on basketball dribbling skills were compared for Grade 5 students.

An analysis of covariance (ANCOVA) for the pretest was carried out to the test for differences between the group means for each of the posttests. Table 5 shows the results of this analysis.

Table 5

Analysis of Covariance for Basketball Dribbling

\begin{tabular}{lcccc}
\hline Source & $d f$ & $F$ & $\eta$ & $p$ \\
\hline${ }^{a}$ Dribbling Score (Pretest) & 1 & 93.30 & .55 & $<.001$ \\
Strategy & 1 & .86 & .01 & .17 \\
$\quad$ error & 74 & $(7.05)$ & & \\
\hline
\end{tabular}

Note: Values enclosed in parentheses represent mean square errors.

${ }^{a}$ The covariate

The second null hypothesis is not rejected since the mean adjusted posttest dribbling score for the Sport Aerobic treatment group $\left(M_{a d j}=21.27\right)$ was not significantly different from the mean adjusted posttest scores for dribbling for the Practice Style group $\left(M_{a d j}=21.93\right), F(1,74)=0.86, p>.05$. The conclusion is that students learning basketball 
dribbling from the Sport Aerobics method did not improve more than the students learning from the Practice Style method.

Hypothesis 3

Students receiving Sport Aerobics instruction in basketball passing will have higher adjusted posttest passing skills scores than students receiving Practice Style instruction.

The corresponding null hypothesis that students receiving Sport Aerobics instruction in basketball passing will have posttest passing scores that are less than or equal to those of students receiving Practice Style instruction was tested.

The scores on basketball passing after an experimental Sport Aerobic basketball instruction strategy were compared to those after a Practice Style basketball instruction strategy for Grade 5 students.

An analysis of covariance (ANCOVA) was then conducted using the pretest score as the covariate to test for differences between group means for each of the adjusted posttest scores for each of the instruction conditions.

Table 6 Analysis of Covariance for Basketball Passing

\begin{tabular}{lcccc}
\hline Source & $d f$ & $F$ & $\eta$ & $p$ \\
\hline Passing Score (Pretest) & 1 & 72.17 & .49 & $<.001$ \\
Strategy & 1 & .00 & .00 & .48 \\
$\quad$ error & 74 & $(16.80)$ & & \\
\hline
\end{tabular}

Note: Values enclosed in parentheses represent mean square errors.

${ }^{a}$ The covariate

The third null hypothesis is not rejected since the mean adjusted posttest dribbling score for the Sport Aerobic treatment group $\left(M_{a d j}=31.20\right)$ was not significantly different from the mean adjusted posttest scores for dribbling for the Practice Style group $\left(M_{a d j}=\right.$ 
$31.25), F(1,74)=0.00, p>05$. The conclusion is that students learning basketball passing using the Sport Aerobics method did not improve more than the students learning using the Practice Style method.

\section{Summary}

The purpose of this study was to investigate the hypothesized advantages of an experimental method called Sport Aerobics over the traditional Practice Style instructional method in teaching grade 5 students the three basketball skills of shooting, dribbling, and passing. The results of the analyses of covariance of the data indicated that Hypothesis 1, which suggested the superiority of the Sport Aerobics method, was not supported.

The analysis of the data for Hypothesis 2 showed that when these scores are adjusted based on pre-instruction scores, the mean adjusted basketball dribbling scores of participants taught using the Sport Aerobics method was not lower than the mean basketball dribbling scores of those students taught using the practice style method. The Hypothesis that the Sport Aerobics method was superior to the Practice Style method was not supported.

The analysis of variance for Hypothesis 3 showed that when these scores were adjusted based on pre-instruction scores, the mean passing skills score of students taught using the Sport Aerobics method was not greater than mean passing skill score of students taught using the practice style method. Hypothesis 3 was not supported, therefore. It was concluded that students learning basketball passing using Sport Aerobics did not improve more than the students learning from the Practice Style method. 
The implications of these findings and recommendations for using the results in future Sport Aerobics research are presented in Chapter V. 


\section{CHAPTER V \\ DISCUSSION}

Chapter 5 summarizes the findings of this study, discusses the meaning of these findings, and makes recommendations for practice and further research. The contributions of the study to the knowledge base will be provided as evidenced within the literature on physical education instruction concerning the acquisition of movement/motor skills in children as a means of further facilitating participation in physical activity. Within this discussion will be an analysis of the relation of this study's findings to the earlier literature in this area. Recommendations for future practice and research in this area will also be addressed.

\section{Summary}

Summaries of the findings for the three research questions are as follows. This will be followed with a summary of all the findings. Effects of Lessons on Basketball Shooting Scores

Research question 1. Do differences exist between the basketball shooting scores of children who received Sport Aerobics instruction, using a combination of techniques including object free movement, movement progression, immediate feedback, specific cueing, and simultaneous group organization, as compared to the scores of those children who received Practice Style Basketball instruction lessons?

Findings. Results of the ANCOVA indicated that students learning basketball shooting from the Sport Aerobics method did not improve more than students learning from the Practice Style method. 
Research question 2. Do differences exist between the basketball dribbling scores of children who received Sport Aerobics instruction, using a combination of techniques including object free movement, movement progression, immediate feedback, specific cueing, and simultaneous group organization, as compared to the scores of those children who received Practice Style Basketball instruction lessons?

Findings. Results of the ANCOVA indicated that students learning basketball dribbling from the Sport Aerobics method did not improve more than students learning from the Practice Style method.

Effects of Lessons on Basketball Passing Scores

Research question 3. Do differences exist between the basketball passing scores of children who received Sport Aerobics instruction, using a combination of techniques including corrective feedback and cueing, object free movement, movement progression, and simultaneous group organization, as compared to the scores of those children who received Practice Style Basketball instruction lessons?

Findings. Results of the ANCOVA indicated that students learning basketball passing from the Sport Aerobics method did not improve more than students learning from the Practice Style method.

In summary, the statistical results of the data did not support the concept that Sport Aerobics instruction, using the research based instructional elements of immediate feedback and specific cueing, object free movement, movement progression, and simultaneous group organization, is preferable to Practice Style instruction for grade five 
students' improvement of basketball skills. Neither shooting, dribbling, nor passing skills improved more for the Sport Aerobic instruction than Practice Style instruction.

\section{Discussion}

The findings suggest complex skills, such as basketball shooting, that require more coordination and timing, be given additional practice time to potentially impact task experiences. The Practice Style activities of drills, primarily focused on shooting with the implement (the basketball), was the opposite of the emphasis on movement mechanics that was the focus of the Sport Aerobics instructional method. Even though Sport Aerobics instruction allowed individual practice time with implement, five minutes may not have been sufficient time for performance production. The Sport Aerobics program may need to fine tune this aspect of its approach to the basketball objectives. It did not provide enough time with the ball for transfer of information for needed subskill acquisition. More extension activities with the ball may be necessary in realistic settings.

Oslin, Stroot, and Siedentop (1997) indicated 60 trials per session, per skill provided enough practice for an average elementary physical education group. The time allotted most physical education programs cannot provide enough time to replicate these results.

Even when more time is allowed for manipulation ( 5 practice trials to 10 practice trials), Rink et al. (1992), indicated students without progress from pretest to posttest of the entire skill had success through progression until the entire skill was to be performed (i.e. volleyball serve over the net even from half-court). Initial success was seen with students at early levels of the progression that lead the researchers to conclude that the instructional objective of learning the entire skill needed changing (Rink et al., 1992). 
Similarly, in this study there may not have been sufficient time for the basketball skill developmental sequences planned.

Even though the cues used in this study represented typical basketball skill terminology (Wissel, 1994), cues may need further refining. Providing cueing is an integral part of the Sport Aerobic method. The literature on cueing points out how complex this important teaching strategy is. Masser (1993) investigated "critical cues" as an efficient instructional method to promote motor skill development. Masser's study compared the use of two critical cues within the cue group, and interestingly even though both groups significantly improved, only one group with a specific cue maintained high level of performance after 2 months. Masser's recommendation was to focus future research on the identification and use of critical cues and influence on motor skill development, and to focus with one or two critical cues, as opposed to 4 or 5 , in order to minimize instructional complexity for teacher and student. He added it should maximize internalization versus externalization processing of movement, thereby promoting transferability.

Singer and Suwanthada (1986) postulated that the absence of reminders or limited frequency of delivering cues may result in an insufficient degree of strategy use, where as too much frequency may cause a redundant effect. According to Singer and Suwanthada, this would interfere with internalization of information or interfere with necessary cognitive activities of the learner to effect transferability toward performance. Sport Aerobics method provided continuous cueing from sub skill to sub skill and lesson to lesson. This may have been too frequent and caused inhibition of internalization and performance outcomes. Literature does not address what is the appropriate amount or 
method of assessing when cue frequency has reached its effectiveness. This measure may be measured subjectively by teacher observation or by student indicating when cueing reaches sufficient frequency.

An additional issue this study addresses is the receiving of information that is affected by external or internal focusing (Wulf, Shea, \& Park, 2001). Wulf, Shea, and Park indicated that learners would internalize information and transfer that information into skill acquisition if they could differentiate between the effectiveness of external and internal foci. Therefore, without sufficient time for the Sport Aerobic group to detect differential effects of their performance, internalization of information may not have been accomplished. A subsequent approach to be tried in the future would be to first present the two foci sources and then let the learners experience the two approaches. Then secondly allow the option to adapt an internal (feet) or external (markers on the floor) focus of attention.

According to Gallahue (1996), the specialized movement phase of development is typically experienced during later childhood and adolescent years (7-14 years old). Graham et al. (1996) indicate that children in the fourth and fifth grades who engage in first time skill development activities, initially have a difficult time adjusting, particularly the children who enjoy playing games they dominate. Therefore, the Sport Aerobics approach may have presented an activity not appropriate for this grade level's developmental readiness (cognitively and affectively). Not having the learners' cooperation for on-task focusing leads to a lack of their internalization of information. This would be seen during their individual practice and in the results of their performance tests. 
It is possible that the sport chosen for this study had a significant impact on the findings of the study. Not only are the age and experience of the learner likely to be factors in the efficacy of a treatment, but the performance of sports is also likely to be a factor that affects results. The complexity of the sport and even perceived difficulty of performing the relevant sports skills in a continuous fashion and in combination with each other may well be inappropriate for children at the specialized phase of skill development.

Rink et al. (1996), present critical concerns about the fact that learners at this age have difficulty in getting to the level of control of an object needed in order to demonstrate adequate performances. Even though Basketball is considered a typical sport activity in elementary school curricula, its complex skills of shooting and dribbling are particularly problematic (Rink, 1986).

Lastly, gauging learners' motivation or desire to improve their skills requires assumption by the researchers. The setting for this study was typical of an elementary physical education class curriculum. Leamers' willingness to apply themselves on a class to class basis affects their refinement of movement and resulting muscle memory outcome. Future consideration may be given to sport likes and dislikes of learners and preferred methods of instruction.

\section{Recommendations}

The findings of this study serve as a basis for several recommendations, both for teaching practice and further research. 
The following recommendations are offered for teaching practice:

1. It is recommended that teachers consider varying approaches to traditional Practice Style instruction with alternate movement refinement strategies. Drills with performance-product outcome as a dominating activity for skill acquisition practice minimizes process outcome importance.

2. Sport Aerobics should be given some consideration within a Practice Style instruction of skill acquisition, since its primary focus is process of movement learning.

3. Students should be given worksheets to enhance movement mechanics. Worksheets would outline cues necessary for cognitive recognition of each skills movement pattern checkpoints.

4. Simultaneous group organization during initial and periodic instruction of skills, especially for complex skills, may facilitate difficulties of learners' development. Simultaneous group organization allows direct and quality corrective feedback to each student during the learning process.

5. Teacher training manuals in alternative instructional strategies that apply to skill acquisition learning as Sport Aerobics instruction should be made available for various physical education curriculums.

The following recommendations are offered for future research:

1. This study was conducted in South Florida in an outdoor activity. A similar study should be conducted in other geographic locations to determine whether the results are generalizable to other locations. 
2. Further studies should involve more extensive and long-term training. A oneyear study with additional fifth grade elementary school students would give the researcher more time to complete the training program with additional teachers and more instructional time with students.

3. The findings of this study showed that Sport Aerobics did not improve basketball skills more than Practice Style instruction. This result suggests that a new study should be conducted that integrates both instructional strategies. A three-group comparison, Practice Style, Sport Aerobic and combined Sport Aerobic and Practice Style strategy may result in a better understanding of the process of skill acquisition achievement.

4. Further studies should consider student enjoyment of the activity and strategy. Whether students' motivation to learn might influence their self-confidence or minimize the intimidation they feel about an activity could be revealed from additional data collection. Survey instruments could be applied and examined to determine relationships of interest, enjoyment, self-confidence, and skill acquisition achievement outcomes.

5. Additional consideration should be given to gender and strategy of instruction. Males and females may respond to teaching strategies differently within a coed physical education class. Classes that are gender segregated may show evidence of gender sensitivities to instructional strategies (Garcia, 1994; Wright, 1995).

6. Instructional strategies have not been designated for staged grade specific developmental education. Other grades may be more appropriate for a Sport 
Aerobic instructional strategy. Therefore, grade comparisons using Sport Aerobics instructional strategy in elementary middle school and high school grades may show that it is more effective at particular grades.

7. This study chose basketball skills within a typical elementary physical education program. Further studies using an uncommon skill may show more effective results from particular instructional strategies for skill acquisition that may be adopted for teaching the skills included in a typical elementary physical education program. 


\section{LIST OF REFERENCES}

Abound, F. E. (1985). Children's application of attribution principles to social comparisons. Child Development, 56, 682-688.

Adams, J. (1971). A closed-loop theory of motion learning. Journal of Motor Behavior, $3,111-150$.

Alpert, B., Field, T., Goldstein, S., \& Perry, S. (1990). Aerobics enhances cardiovascular fitness and agility in preschoolers. Health Psychology, $9(1), 48-56$.

American Alliance for Health, Physical Education, Recreation \& Dance (1984). Basketball for boys and girls; skill test manual. Reston, VA: Author

Anderson, L. W., \& Scott, C. C. (1978). The relationship among teaching methods, student characteristics, and student involvement in learning. Journal of Teacher Education, 29(3), 53-57.

Baddeley, A. D., \& Longman, D. J. A. (1978). The influence of length and frequency of training session on the rate of learning to type. Ergonomics, 21, 627-635.

Buck, M., Harrison, J. M., \& Bryce, G. R. (1990). An analysis of learning trials and their relationship to achievement in volleyball. Journal of Teaching in Physical Education, 10, 134-152.

Centers for Disease Control and Prevention. (1997). Guidelines for school and community programs to promote lifelong physical activity among young people. Morbidity and Mortality Weekly Reports, 46 (No. RR-6): 1-36.

Cook, T. D., \& Campbell, D. T. (1979). Quasi-experimentation: Design and analysis issues for field settings. Chicago: Rand McNally.

Coull, J., Tremblay, L., \& Elliott, D. (2001). Examining the specificity of practice hypothesis: Is learning modality specific? Research Quarterly for Exercise and Sport, 72, 345-354.

Elliott, D., Chua, R., Pollock, B. J., \& Lyons, J. (1995). Optimizing the use of $\mathrm{v}^{*}: \mathrm{z}$ in manual aiming: The role of practice. The Quarterly Joumal of Experimental Psychology, 48, 72-83.

English, F. (1983). Fundamental curriculum decisions. Alexandria, VA: Association for Supervision and Curriculum Development. 
French, K. E., Werner, P., Taylor, K., Hussey, H., \& Jones, J. (1996). The effects of a 6week unit of tactical, skill, or combined tactical and skill instruction on badminton performance of ninth-grade students. Journal of Teaching in Physical Education, $15,439-463$.

Gabbard, C., LeBlanc, E., \& Lowy, S. (1987). Physical education for children. Englewood Cliffs, NJ: Prentice-Hall.

Gallahue, D. L. (1997). Developmental physical education for today's children. Dubuque, IA: Brown \& Benchmark.

Gallahue, D. L., \& Ozmun, J. C. (1995). Understanding motor development: infants, children, adolescents, adults. Dubuque, IA: Brown \& Benchmark.

Garcia, C. (1994). Gender differences in young children's interactions when learning fundamental motor skills. Research Quarterly for Exercise and Sport, 65, 213-225.

Graham, G., \& Heimerer, E. (1981). Research on teacher effectiveness: a summary with implications for teaching. Quest, 33(1), 14-25.

Graham, G., Holt/Hale, S. A., \& Parker, M. (1996). Children moving, a reflective approach to teaching physical education $\left(4^{\text {th }}\right.$ ed.). Mountain View, CA: Mayfield.

Graham, K. C., Ellis, S. D., Williams, C. D., Kwak, E. C., \& Werner, P. H. (1996). Highand low-skilled target students' academic achievements and instructional performance in a 6-week badminton unit. Joumal of Teaching in Physical Education, 15, 477-489.

Gribbons, B., \& Herman, J. (1997). True and quasi-experimental designs. Practical Assessment, Research \& Evaluation, 5(14), 22-27.

Griffin, L. (1996). Improving net/wall game performance. Journal of Physical Education, Recreaction, and Dance, 67(2), 34-37.

Griffin, L., Dodds, P., \& Rovegno, I. (1996). Pedagogical content knowledge for teachers: Integrate everything you know to help students learn. Journal of Physical Education, Recreation, and Dance, 67(9), 58-61.

Hastie, P. A. (1996) Student role involvement during a unit of sport education. Journal of Research in Physical Education, 16,88-103.

Kirk, R. (1995). Experimental design: Procedures for the behavioral sciences ( ${ }^{\mathrm{rd}}$ ed.). Pacific Grove, CA: Brooks/Cole. 
Lowry, R., Howell, W., Kann, L., \& Collins, J. (2001). Recent trends in participation in physical education among U.S. high school students. Journal of School Health, $71,145-152$.

Magill, R. A. (1990). Motor learning is meaningful for physical educators. Quest, 42, 136-133.

Magill, R. A. (1993). Motor learning: Concepts and applications. Dubuque, IA: Brown.

Masser, L. S. (1993). Critical cues help first-grade students' achievement in handstands and forward rolls. Journal of Teaching in Physical Education, 12, 301-312.

McDonald, F. (1976). Report on Phase II of the beginning teacher evaluation study. Journal of Teacher Education, 27(1), 39-42.

McKenzie, T. L., Alcaraz, J. E., \& Sallis, J. F. (1994). Assessing children's liking for activity units in an elementary school physical education curriculum. Journal of Teaching in Physical Education, 13, 206-215.

McKiddie, B., \& Maynard, I. W. (1997). Perceived competence of school children in physical education. Journal of Teaching in Physical Education, 16, 324-339.

McPherson, S. (1992, June). Instructional influences on longitudinal development of beginners' knowledge representation between points in tennis. Paper presented at the annual meeting of the North American Society for the Psychology of Sport and Physical Activity, Pittsburgh, PA.

McPherson, S., \& French K. (1991). Changes in cognitive strategy and motor skill in tennis. Journal of Sport \& Exercise Psychology, 13, 26-41.

Medley, D. M. (1979). Research on teaching: Concepts, findings and implications. Berkeley, CA: McCutchan

Mosston, M., \& Ashworth, S. (1986). Teaching physical education, ( ${ }^{\text {rd }}$ ed.). New York: Maxwell Macmillan International.

National Association for Sport and Physical Education (NASPE). (1992). Developmentally appropriate physical education practices for children. A position statement on physical education for children of NASPE. Reston, VA: American Alliance for Health, Physical Education, Recreation, and Dance. 
National Association for Sport and Physical Education (NASPE). (1995a). Moving into the future: National Standards for Physical Education. Reston, VA: American Alliance for Health, Physical Education, Recreation, and Dance.

National Association for Sport and Physical Education (NASPE). (1995b). Looking at physical education from a developmental perspective: A guide to teaching. A position paper of the motor development task force of NASPE. Reston, VA: American Alliance for Health, Physical Education, Recreation, and Dance.

National Association for Sport and Physical Education (NASPE). (1995c). Moving into the future: National Physical Education Standards: $A$ guide to content and assessment. Reston, VA: American Alliance for Health, Physical Education, Recreation, and Dance.

National Institute of Diabetes and Digestion and Kidney Diseases of the National Institute of Health. Statistics related to overweight and obesity. Retrieved November 21, 2002 from http://www.niddk.nih.gov/health/nutrit/pubs/statobes.htm\#research

National Institute of Health. (1995). Physical activity and cardiovascular health: NIH Consensus Statement. Kensington, MD: NIH Consensus Program Information Center.

Oslin, J., Stroot, S., \& Siedentop, D. (1997). Use of component-specific instruction to promote development of the overarm throw. Journal of Teaching in Physical Education, 16, 340-356.

Rikard, G. L. (1991). The short term relationship of teacher feedback and student practice. Journal of Teaching in Physical Education, 10, 275-285.

Rikard, G. L. (1992). The relationship of teachers' task refinement and feedback to students' practice success. Journal of Teaching in Physical Education, 11, 349-357.

Rink, J. E. (1986). Teaching physical education for learning. St. Louis, MO: Times Mirror/Mosby.

Rink, J. E. (1993). Teaching physical education for learning ( $2^{\text {nd }}$ ed.). St. Louis: Times Mirror/Mosby.

Rink, J. E., French, K. E., \& Tjeerdsma, B. L. (1996). Foundations for the learning and instruction of sport and games. Journal of Teaching in Physical Education,15, $399-417$. 
Rink, J. E., French, K. E., Werner, P. H., Lynn, S., \& Mays, A. (1992). The influence of content development on the effectiveness of instruction. Journal of Teaching in Physical Education, 11, 139-149.

Roberts, G. C. (1984). Toward a new theory of motivation in sport: The role of perceived ability. In J.M. Silva and R.S. Weinberg (Eds.), Psychological foundations of sport (pp. 214-228). Champaign, IL: Human Kinetics.

Ross, J. G., Dotson, C. O., Gilbert, G. C., \& Katz S. J. (1985). The National Children and Youth Fitness Study: What are kids doing in school physical education? Journal of Physical Education, Recreation, and Dance, 56, 3-76.

Rotella, R. J., Hanson, T., \& Coop, R. H. (1991). Burnout in youth sports. Elementary School Journal, 91, 421-428.

Rudisill, M. E., Mahar, M. T., \& Meaney, K. S. (1993). The relationship between children's perceived and actual motor competence. Perceptual and Motor Skills, $76,895-906$.

Sallis, J. F., \& Patrick, K. (1994). Physical activity guidelines for adolescents: Consensus statement. Pediatric Exercise Science, 6, 302-314.

Schmidt, R. A. (1975). A schema theory of discrete motor skill learning. Psychological Review, 76, 383-393.

Siedentop, D. (1991). Developing teaching skills in physical education $\left(3^{\text {rd }}\right.$ ed.). Mountain View, CA: Mayfield.

Silverman, S. (1993). Student characteristics, practice, and achievement in physical education. Journal of Educational Research, 87, 54-61.

Singer, R., \& Suwanthada, S. (1986). The generalizability effectiveness of a learning strategy on achievement in related closed motor skills. Research $Q$ uarterly for Exercise \& Sport, 57, 205-214.

Stipek, D., \& McIver, D. (1989). Developmental change in children's assessment of intellectual competence. Child Development, 60,521-538.

Trochim, W. (1999). The research methods knowledge base. Cincinnati, $\mathrm{OH}$ : Atomic Dog Publishing.

Turner, A., \& Martinek, T. (1992). A comparative analysis of two models for teaching games (technique approach and game-centered (tactical focus) approach). International Journal of Physical Education, 29, 131-152. 
Turner, A., \& Martinek, T. (1995, April). An investigation into teaching games for understanding: Effects on skill, knowledge and game play. Paper presented at the annual meeting of AERA, San Francisco, CA.

Tyler, R. (1949). Basic principles of curriculum and instruction. Chicago: The University of Chicago Press.

U.S. Department of Health and Human Services. (1996). Physical Activity and Health: A Report of the Surgeon General. Atlanta, GA: U.S. Dept of Health and Human Services, Centers for Disease Control and Prevention, National Center for Chronic Disease Prevention and Health Promotion.

U.S. Department of Health and Human Services. (2001). Physical Activity and Health: A Report of the Surgeon General. Atlanta, GA: U.S. Dept of Health and Human Services, Centers for Disease Control and Prevention, National Center for Chronic Disease Prevention and Health Promotion.

Vogel, P., \& Seefeldt, V. (1988). Program design in physical education. Indianapolis: Benchmark Press.

Werner, P. H., \& Rink, J. E. (1989). Case studies of teacher effectiveness in second grade physical education. Journal of Teaching in Physical Education, 8, 280-297.

Wissel, H. (1994). Basketball steps to success. Champaign, IL: Human Kinetics.

Wright, J. (1995). A feminist poststructuralist methodology for the study of gender construction in physical education: Description of a study. Journal of Teaching in Physical Education, 15, 1-24.

Wulf, G., Shea, C., \& Park, J. (2001). Attention and motor performance: Preference for and advantages of an external focus. Journal of Exercise and Sport, 72, 335-344. 
APPENDICES 
Appendix A

Overall Design of the Study 
OVERALL DESIGN OF THE STUDY

\begin{tabular}{|c|c|c|c|c|c|c|}
\hline & \multicolumn{6}{|c|}{ STUDENTS SCORES } \\
\hline \multirow[b]{2}{*}{ Strategy } & \multicolumn{6}{|c|}{ SKILL ACQUISITION } \\
\hline & \multicolumn{2}{|c|}{ Dribbling } & \multicolumn{2}{|c|}{ Shooting } & \multicolumn{2}{|c|}{ Passing } \\
\hline $\begin{array}{r}\text { Sport } \\
\text { Aerobics }\end{array}$ & PRE & POST & PRE & POST & PRE & POST \\
\hline $\begin{array}{r}\text { Practice } \\
\text { Style }\end{array}$ & & & & & & \\
\hline
\end{tabular}




\section{Appendix B}

Basketball Skills Curriculum Schedule for Both Methods of Instruction (Shooting, Dribbling, Passing) 

INSTRUCTION (SHOOTING, DRIBBLING, PASSING)

\section{$S=S P O R T$ AEROBICS METHOD $P$ = PRACTICE STYLE METHOD}

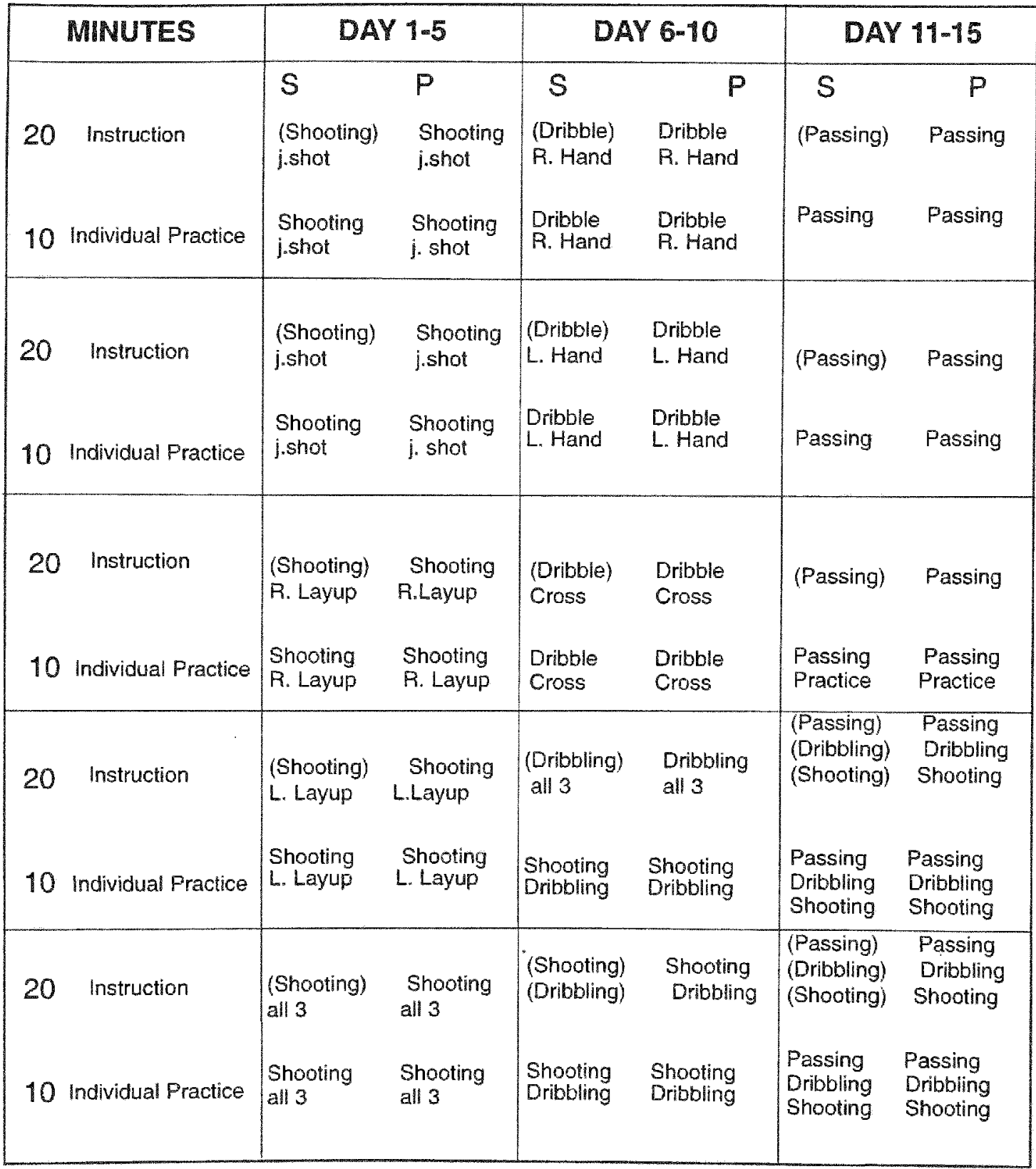

Items in parentheses in rows are devoted to Sport Aerobics training; ie. instruction for developing skilis and movements without implements, using music and continual body flow. 
Appendix C

Score Sheet 
Teacher

Test 1: Day

Time

Test 2: Day Time

\begin{tabular}{|c|c|c|c|c|c|c|}
\hline \multirow{2}{*}{ STUDENT NAME } & \multicolumn{2}{|c|}{ JUMP SHOT } & \multicolumn{2}{|c|}{ DRIBBLE } & \multicolumn{2}{|c|}{ PASS } \\
\hline & TEST 1 & TEST 2 & TEST 1 & TEST 2 & TEST 1 & TEST 2 \\
\hline & & & & & & \\
\hline & & & & & & \\
\hline & & & & & & \\
\hline & & & & & & \\
\hline & & & & & & \\
\hline & & & & & & \\
\hline & & & & & & \\
\hline & & & & & & \\
\hline & & & & & & \\
\hline & & & & & & \\
\hline & & & & & & \\
\hline & & & & & & \\
\hline & & & & & & \\
\hline & & & & & & \\
\hline & & & & & & \\
\hline & & & & & & \\
\hline & & & & & & \\
\hline & & & & & & \\
\hline & & & & & & \\
\hline & & & & & & \\
\hline & & & & & & \\
\hline & & & & & & \\
\hline & & & & & & \\
\hline & & & & & & \\
\hline & & & & & & \\
\hline
\end{tabular}


Appendix D

Sport Aerobics

Basketball Skill Development 


\section{SPORT AEROBICS \\ BASKETBALL SKILL DEVELOPMENT}

\section{DAY 1}

Jump Shot

Cues

Feet: shoulder width apart, non-shooting foot planted first, shooting foot slightly forward

Knees: slightly bent, Hips: flexed Elbows: in and bent Shooting Hand: under ball

Non-Shooting Hand: on side of ball, Eves: look at front of rim, Extend Legs, hips, then arm, writ flexes, with finger pads fingers project to target.

shooting position stance, footfires, shooting position stance, knee lifts, shooting

position stance, skipping, shooting position stance, running on the spot, shooting

position stance, side slide, shooting position stance, box step, shooting position stance.

Routine 1 = Feet only

Routine 2 = Feet and Lower Body

Routine $3=$ Hands Only

Routine 4 = Feet, Lower Body and Hands

\section{DAY 2}

\section{Right Lay-up}

Cues Non-Shooting leg: planted, Shooting Leg: knee up, Shooting Arm: Elbow bent, Shooting Hand: under ball, Non-Shooting Hand: side of ball, Arm: extends to basket.

ready position stance, plant left foot, right knee up, footfires, left foot plant, right knee up, side leaps, left foot plant, right knee up, arm extends to basket, running on spot, plant left foot, right knee up, extend arm, jump squats.

Combination: running on spot, jump shot, footfires, right lay-up, side slide, jump shot, right lay-up, box step, jump shot, knee lifts, right lay-up (repeat). 


\section{DAY 3}

\section{Left Lay-up}

Cues

Non-shooting leg: planted, Shooting Leg: knee up, Shooting Arm: Elbow bent, Non-Shooting Hand: side of ball, Shooting Hand: under ball, Shooting Arm: extends to basket.

ready position stance, plant left foot, right knee up, footfires, left foot plant, right knee up, side leaps, left foot plant, right knee up, arm extends to basket, running on spot, plant left foot, right knee up, extend, jump squats.

Combination: heel kicks, jump shot, footfires, right lay-up, box step, left lay-up, jump squats, jump shot, running on spot, right lay-up, side leaps (repeat).

\section{DAY 4}

\section{All Three}

Shooting Skills Knee lifts, jump shot, slide, jump shot, right lay-up, rebound, left lay-up, box step, jump shot, footfires, right lay-up, jump squats, left lay-up, skipping, jump shot, running on spot, right lay-up, slide, left lay-up, rebound (repeat).

Routine 1 = Lines

Routine 2 = Wave

\section{DAY 5}

\section{Control Dribble Right}

Cues Left foot forward, Waist bent, lean forward slightly, left arm protects the ball, Bight Arm out to right side at waist level, Elbow bent, Right Hand on top of ball.

Knee lifts, dribble right, footfires, dribble right, side leaps, dribble right, running on the spot, dribble right, jump squats, dribble right, box step, dribble right.

Routine $1=$ Stationary control dribble

Routine 2 = Wave

Routine 3 = Wave control dribble, jump shot, lay-up right, lay-up left 


\section{DAY 6}

\section{Dribble Left}

Cues

Right foot forward, Waist bent, lean forward slightly, Right Arm protects the ball, Left Arm :out to left side, Elbow bent, Left Hand on top of ball.

Control dribble left, leg extensions, control dribble left, side shuffles, control dribble left, box step, control dribble left, running on the spot, control dribble left, jump squats, control dribble left, knee lifts.

Routine 1 = Stationary control dribble Routine 2 = Wave

Routine 3 = Wave control dribble right, control dribble left, jump shot, left lay-up, right lay-up

\section{DAY 7}

\section{Cross Dribble}

Cues

Dribble position weight primarily on right foot, Right Hand: dribbles, Left Foot: lifts, moves across body, plants left, Right Dribble Arm: crosses body, weight shifts to left foot, Right Foot: moves forward, Left Hand dribbles, Right Foot:

lifts, moves across body, plants right, Left Arm crosses body. dribble right, cross dribble left, dribble left, foot shuffles, dribble left , cross dribble, dribble right, heel kicks, dribble right, cross dribble, dribble left, cross dribble, dribble right, running on the spot with dribble right, cross dribble, dribble left with running on the spot.

Combination:knee lifts, jump shot, right dribble, cross dribble, left dribble, footfires, right lay-up, heel kicks, left lay-up, side shuffles, jump shot, running on the spot, right dribble, cross dribble, left dribble, leg extensions, left lay-up, right lay-up, side leaps (repeat).

Routine 1 = Stationary cross dribble

Routine 2 = Wave cross dribble

Routine $3=$ Wave combination 


\section{DAY 8}

\section{All Three}

\section{Dribbles plus shooting lay-ups}

running on the spot, dribble right, cross dribble, dribble left, jump shot, heel kicks, right lay-up, footfires, left lay-up, side kicks (repeat).

Routine 1 = Stationary

Routine 2 = Wave

Combination day 7

Combination day 7

\section{DAY 9}

\section{Chest Pass}

Cues Feet: shoulder width apart weight slightly on heels, Knees: flexed, Chest: facing target, Hands: at chest facing target, Eves: looking at center of target, One Leg: steps toward target, weight shifts to front leg, Arms: extend straight, evenly toward target, Hands: turn palms facing out, fingers point to target.

pass position, running on spot, pass position and step heel kicks, pass position and step and arms extend palms facing out, fingers point to target, side leap, complete pass, box step, complete pass.

Combination: Wave- chest pass, jump shot, running on spot, dribble right with running on spot, cross dribble, dribble left with running on the spot, heel kicks, lay-up right, lay-up left, footfires, jump shot, chest pass, lay-up right, lay-up left, box step, dribble left, cross dribble, dribble right (repeat).

Routine $1=$ Stationary pass

Routine 2 = Wave pass

Routine 3 = Stationary combination

Routine 4 = Wave combination

DAY 10

Chest Pass

Cues

same as day 9 
DAY 11

Defense Side Slide

Cues Feet: shoulder width apart, Knees: bent, Hips: bent, Torso:

square with feet, Hands: out front, Weight: on balls of feet, Lift one leg out to side, Lift other leg pull in towards other leg

Wave: side slide, running on spot, side slide, heel kicks, side slide, side shuffles, side slide, skipping, side slide, box step, side slide, leg extensions, side slide, side leaps, knee lifts, side slide, foot shuffles, side slides, footfires, side slide.

Combination: Footfires, jump shot, side leaps, dribble right, cross dribble, dribble left, left lay-up, running on spot,dribble left, cross dribble, dribble right, right lay-up, box step, chest pass, side shuffles, side slide (repeat).

Routine 1 = Stationary side slide

Routine 2 = Wave side slide

Routine 3 = Stationary combination

Routine $4=$ Wave combination

\section{DAY 12}

\section{Defense Drop Slide}

Cues Feet: shoulder width apart, Knees: bent, Hips: bent, Torso: square with feet, Hands: out front, Weight: on balls of feet, Lift: one leg, Pivot: on opposite leg, Plant: lifted leg behind, Weight :shifts on to pivot foot

Wave: drop slide left, drop slide right, ready position, side slide, drop slide right, side slide, drop slide left, footfires, drop slide right, running on spot, drop slide left, heel kicks, drop slide left, drop slide right, foot shuffles.

Routine 1 = Stationary drop slides

Routine 2 = Wave drop slides

Routine $3=$ Stationary combination

Routine $4=$ Wave combination 
Appendix E

Practice Style

Basketball Skill Development 
5-10 minutes: Introduction of Skill: importance when used

Demonstraton how to how not to

10 minutes Cues skill components

5-10 minutes

Drills ${ }^{*} \quad$ formations

Practice free time (any skill they choose)

*as outlined - others are acceptable if time permits

\section{DAY 1}

\section{Jump Shot}

Cues

Feet: shoulder width apart, non-shooting foot planted first, shooting foot slightly forward

Knees: slightly bent, Hips: flexed Elbows: in and bent Shooting Hand: under ball

Non-Shooting Hand: on side of ball

Shoot straight up - retrieve shot

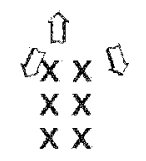

Wall Shot - retrieve shot

same formation

Basket Shot - retrieve shot

$$
\begin{aligned}
& x \times \times x>0 \\
& x \times x \times 1
\end{aligned}
$$

\section{DAY 2}

\section{Right Lay-up}

Cues Non-Shooting leg: planted, Shooting Leg:

knee up, Shooting Arm: Elbow bent, Shooting Hand: on top of ball, $x \times x \Rightarrow x \times x$ Non-Shooting Hand: side of ball, Arm: extends to basket

Line Lay-up (one step) retrieve line $x x x$

Basket Lay-up Right shooting line $x \times x>0$ Combination: Basket jump shot (retrieve shot) $x \times x>0$ 


\section{DAY 3}

\section{Left Lay-up}

Cues Nonshooting leg: planted, Shooting Leg: knee up, Shooting Arm: Elbow bent, Non-Shooting Hand: side of ball, Shooting Hand: on top of ball, Shooting Arm: extends to basket.

$$
\begin{aligned}
& \text { Line Lay-up (one step) } \quad x \times x \Rightarrow x \times x \\
& \begin{array}{r}
\text { Basket Lay-up Left } \quad \begin{array}{l}
\text { shooting line } x \times x \\
\text { retrieve line } x \times x>0
\end{array}
\end{array}
\end{aligned}
$$

Combination: Basket Lay-up Right

Basket jump shot $\begin{aligned} & \text { (retrieve } \\ & \text { shot) }\end{aligned} \times \times \times \times>0$

\section{DAY $4 / 5$}

All Three Shots Review cues of all shooting skills Jump shot Shoot straight up - retrieve shot Wall shot - retrieve shot $x \times x \times>0$ Basket Shot - retrieve shot Line-up (one-step)

Basket Lay-up right/left

\section{DAY 6}

\section{Control Dribble Right}

Cues Left foot forward, Waist bent, lean forward slightly, left arm protects the ball, Right Arm out to right side at waist level, Elbow bent, Right Hand on top of ball

Stationary Dribble (10 seconds \& pass)

$$
\begin{aligned}
x \times \times & \text { pass } x \times x \\
\times \times x & =\sigma^{x \times x}
\end{aligned}
$$$$
\text { Line Dribble (20 feet apart) }
$$ 
DAY 7

Dribble Left

Cues Right foot forward, Waist bent, lean forward slightly, Right Arm protects the ball, Left Arm :out to left side, Elbow bent, Left Hand on top of ball.

Stationary Dribble (10 seconds \& pass) $\quad x \times x$ pass $x \times x$

Line Dribble (20 feet apart)

$$
x \times x \Rightarrow \varepsilon^{x \times x}
$$

\section{DAY 8}

\section{Cross Dribble}

Cues Dribble position weight primarily on right foot, Right Hand:

dribbles, Left Foot: lifts, moves across body, plants left, Right

Dribble Arm: crosses body, weight shifts to left foot, Right Foot: moves forward, Left Hand dribbles, Right Foot: lifts, moes across body, plants right, Left Arm crosses body

Stationary Dribble (10 seconds \& pass)

$$
x \times x \text { pass } x \times x
$$

Line Dribble (20 feet apart)

$$
x \times x \Rightarrow \sigma_{x x}
$$

\section{DAY $9 / 10$}

\section{All Three Dribbles}

Review cues of dribbles \& shooting

Stationary dribble right

Stationary dribble left

Line dribble left \& right

Stationary cross dribble

Line dribble cross dribble

Jump shots jump sho, lay-up right \& left 
Feet: shoulder width apart weight slightly on heels, Knees: flexed, Chest: facing target, Hands: at chest facing target, Eyes: looking at center of target, One Leg: steps toward target, weight shifts to front leg, Arms: extend straight, evenly toward target, Hands: turn palms facing out, fingers point to target.

Line Pass (extend arms only)

Pass \& Follow (step \& extend arms) $\quad x \times x \Rightarrow b^{x} \times x$

DAY 13

Chest Pass

Cues

Chest Pass Review

Line Pass

Pass \& Follow

Combination (shots, lay-ups, dribbles)

DAY $14 / 15$

Passing / Dribbling / Shooting Cues

Review Cues

Line Pass

Pass \& Follow

Combination (shots, lay-ups, dribbles) 
Appendix $F$

Sport Aerobic

Skill Acquisition Scores 
Sport Aerobics Skill Acquisition Scores

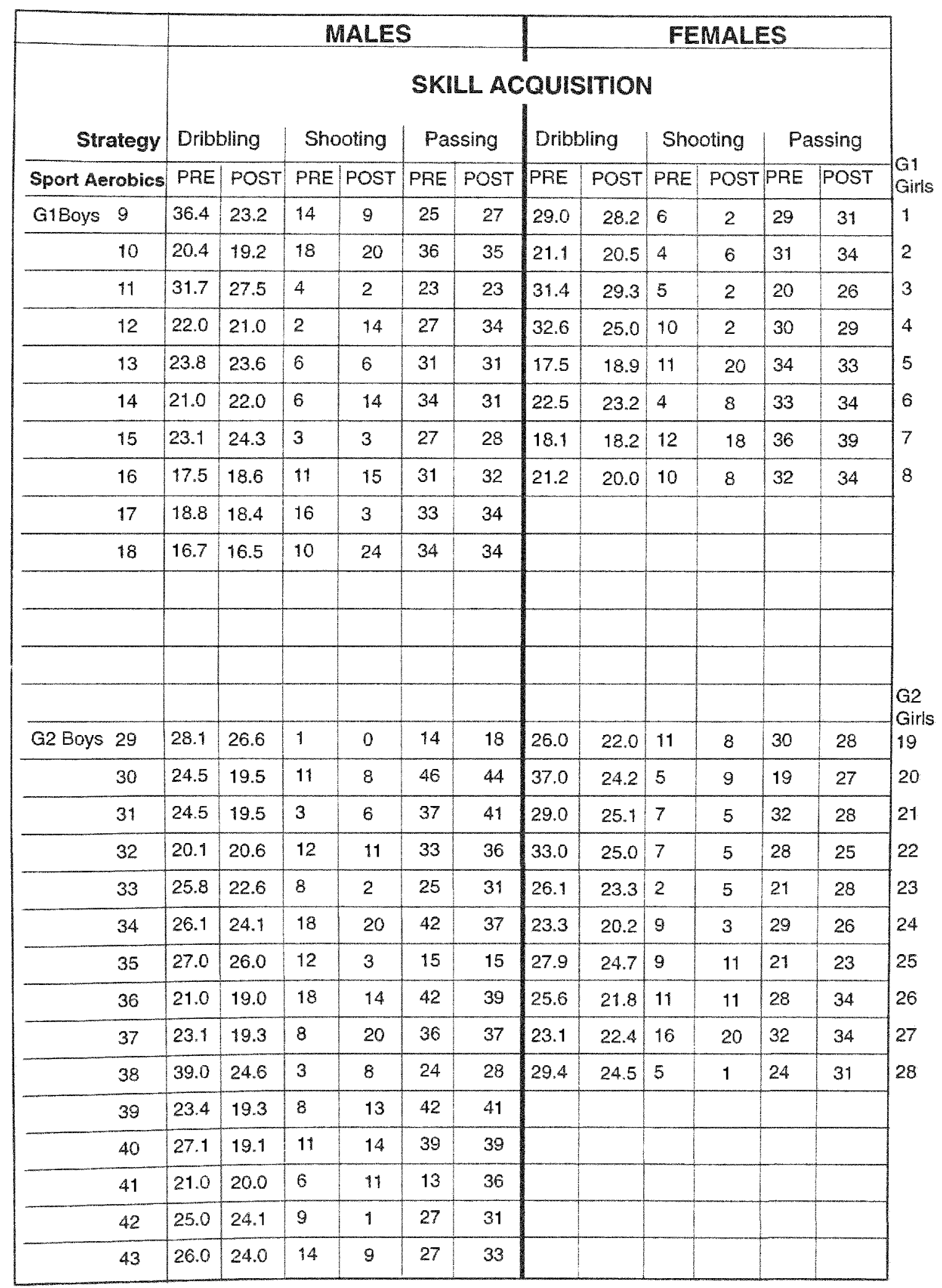


Appendix $G$

Practice Style

Skill Acquisition Scores 
Practice Style Skill Acquisition Scores

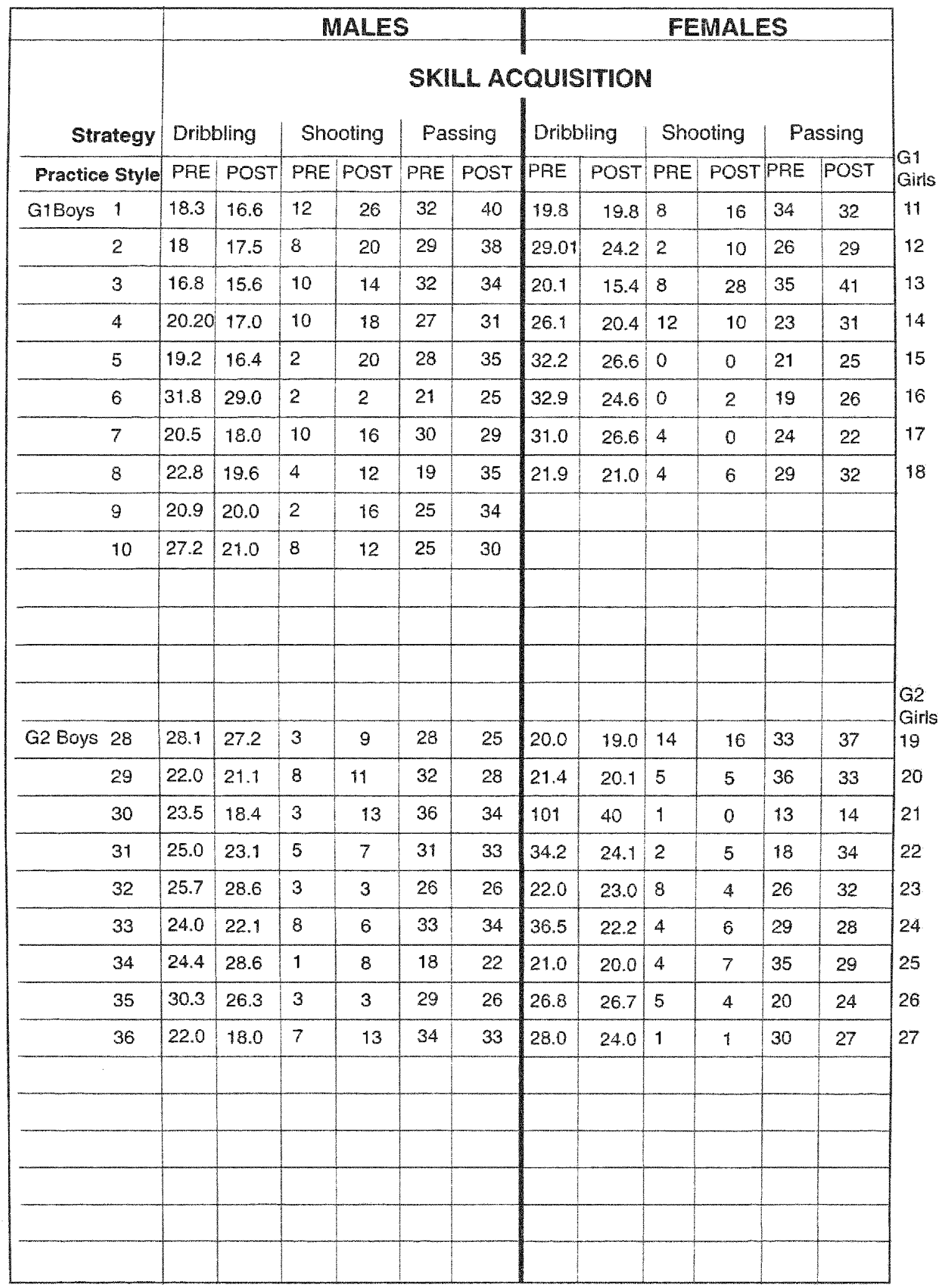


Appendix $\mathrm{H}$

Parent/Guardian of Participant Consent Form 


\section{Consent to participate in a research study \\ The Effect of Basketball Sport Aerobics on Basketball Skill Development for children}

Ifreely and voluntarily give my consent for my child to be a participant in the research project entitled The effect of Basketball Sport Aerobics on Basketball Skill Development for children to be conducted at my childs University of Miami Summer Camp during the summer of 2001 with Bill Elizuk, from Florida International University. I understand that this experiment will last approximately 30 minutes per physical activity class.

I understand that the purpose of this study is to study methods of teaching involving 60 students. This study will research the effectiveness of an exercise activity that promotes basketball skill development. I understand the research procedures that my child will be a part of are as follows: The activity will incorporate skill movements and cardiovascular conditioning with music for each 20 minute physical activity class during four weeks of summer camp. I understand that there are minimal risks involved in my child s participation, since the components of this activity are of routine physical education classes. I have been told that my childs responses will be kept strictly confidential. All scores will be identified only by a code number and my child s performance will not be revealed to anyone without my express permission. This study may benefit your child s basketball skill development if this method is an effective alternative to current methods.

We are asking your permission for your child to participate and complete any questionnaires related to this activity. The questions will ask students about enjoyment of the physical activity. Also, for research purposes only, we are asking your permission to take video footage of your child while participating in this program.

There is no charge to me or my child in this study. My child will not be compensated for participation. I understand that I may withdraw my consent and discontinue my child s participation in this research project at any time with no negative consequences. My child and I have been given the right to ask questions concerning the procedure and any questions have been answered to my and my child s satisfaction. I understand that if any new findings are developed during the time that my child is in this study which may affect my willingness to allow my child to continue to be in the study, I will be informed as soon as possible.

$I$ understand that if $I$ desire further information about this research I should contact Bill Elizuk at 305-348-3486 or faculty supervisor Dr. Yongue 305-348-3783. I also understand that if I have any questions concerning the rights of human subjects, I may contact the Institutional Review Board Chairperson at Florida International University, Dr.Bernard Gerstman at 305-348-3115. I have been offered a copy of this Informed Consent form.

I have read and I understand the above. In addition, I give consent for my child to participate.

Signature of Parent/Guardian Date

I have explained and defined in detail the research procedure in which the participant has agreed to participate and have offered himher a copy of this informed consent form.

Signature Witness Date 
WILLIAM J. ELIZUK

October 6,1955

1982

1984

1985

1986

1991

1998 - Present

1982 - Present

$1983-1985$

$1983-2002$

1986-Present

$1988-1995$
Born, Oshawa, Ontario, Canada

Miami Dade Community College - North Campus

A.A.; Physical Education

American College of Sports Medicine - Adelphi University,

Garden City, NY. Certification as Exercise Test Technologist

Dr. Kenneth Cooper's Aerobic Institute - Dallas, Texas

Certification as Exercise Specialist

Florida International University

B.S.; Physical Education / Exercise Physiology

Florida Intemational University

M.S; Health Education / Exercise Physiology

American Red Cross - First Aid / CPR Certified

Sports Official: Basketball /Woman \& Men's College, FHSAA

Miami Dade Community College - Coordinator of Fitness Testing /

Program Development, Adjunct Instructor

Pritikin Longevity Center, Assistant Exercise Leader

Southem Bell Test Technologist

1000 Employees Fitness Assessment

Florida International University, Adjunct Instructor

Personal Trainer - Executives, Professional Athletes, Division 1 Athletes, Private Clients

Bodyworks Lifestyle Health \& Finess Center

Assistant Manager- Human Performance Fitness Lab \& Service

General Manager; Service, Operations and Membership Sales

Fundraising - Florida Intemational University - Campus Recreation, Coordinator of Fitness Programs \& Development,

Strength and Conditioning Coach

Broward Community College, Adjunct Instructor 


\author{
1996 - Present Director, Producer, National Presenter \\ Award Winning - Sport Acrobics Videos \& Certifications \\ 1999-2001 Bary University, Adjunct Instructor \\ Florida International University \\ Intramural Department Coordinator
}

MAR-JCC

Sports, Leagues, Health \& Fitness Director, youth through adult programming

2001 - Present $\quad$ Broward Community College, Adjunct Instructor

\title{
PUBLICATIONS AND PRESENTATIONS
}

Elizuk, W.E. (April, 1983). Relationship Between Scientific Exercise and Atherosclerosis. Capstone Honors Project Presented at Miami Dade Community College, Miami, Florida

Elizuk, W.E. (July, 1985). Wellness of the Gifted Children. Paper presented at Miami Dade Community College, Miami, Florida.

Elizuk, W.E. (September, 1985). Relationship of Scientific Exercise and Atherosclerosis. Presented, Human Awareness Week, Miami Dade Community College, Miami, Florida 